\title{
Numerical investigations of a pseudo-2D spout fluidized bed with draft plates using a scaled discrete particle model
}

\author{
Vinayak S. Sutkar ${ }^{\mathrm{a}}$, Niels G. Deen ${ }^{\mathrm{a}, *}$, Bhageshvar Mohan ${ }^{\mathrm{a}}$, Vitalij Salikov ${ }^{\mathrm{b}}$, \\ Sergiy Antonyuk ${ }^{\mathrm{b}}$, Stefan Heinrich ${ }^{\mathrm{b}}$, J.A.M. Kuipers ${ }^{\mathrm{a}}$ \\ a Multiphase Reactors Group, Department of Chemical Engineering and Chemistry, Eindhoven University of Technology, P.O. Box 513, 5600 MB Eindhoven, \\ The Netherlands \\ ${ }^{\mathrm{b}}$ Institute of Solids Process Engineering and Particle Technology, Hamburg University of Technology, 21071 Hamburg, Germany
}

\section{H I G H L I G H T S}

- We studied the hydrodynamics of a spout fluidized bed with draft plates.

- Discrete particle simulations are compared with experimental data.

- Scaled-discrete particle simulations are performed to reduce the computational time.

\section{A R T I C L E I N F O}

\section{Article history:}

Received 15 April 2013

Received in revised form

26 September 2013

Accepted 5 October 2013

Available online 12 October 2013

Keywords

Spout fluidized beds

Draft plates

Discrete particle model

Coarse graining

CFD

Fluid mechanics
G R A P H I C A L A B S T R A C T

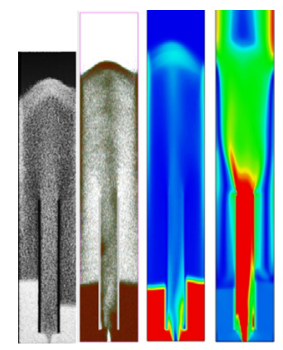

\begin{abstract}
A B S T R A C T
Spout fluidized beds are often utilized for the gas-solid operations involving physical and/or chemical transformations such as drying, coating, granulation, combustion, gasification, etc. This is because these beds combine advantages of both spouted and fluidized beds. Following the spout fluidized bed development, several geometrical modifications have been proposed to optimize the bed performance. One of the modifications includes a draft tube insertion inside the bed, which results in improved performance by providing a restriction on particle cross flow. Moreover, the draft tube insertion leads to a stable spouting at lower flow rates, due to the reduced inlet gas bypassing (from spout to the annulus).

In this work, a discrete particle model (DPM) with a sub-grid scale (SGS) turbulence model was used to simulate the bed dynamics and analyze the effects of the draft plates and particles physical properties by considering two regimes namely, the spouting-with-aeration and fluidized bed-spouting-withaeration (dispersed spout), which are of interest from an industrial point of view. The obtained results were compared with our experimental data (Sutkar et al., 2013b) from particle image velocimetry (PIV) and digital image analysis (DIA). Furthermore, an alternative simulation approach has been used to simulate dynamics of the industrial scale gas-solid contactors consisting very large particles with reduced total computational time by changing the physical properties of the particles to maintain constant Archimedes and Reynolds numbers. The obtained results were compared with the experimental data, as well as with simulation data obtained with the original physical properties.
\end{abstract}

(c) 2013 Elsevier Ltd. All rights reserved.

\footnotetext{
* Corresponding author. Tel.: +31 40 2473681; fax: +31 402475833 .

E-mail address: N.G.Deen@TUe.nl (N.G. Deen).
}

\section{Introduction}

Spout fluidized beds are often applied for the gas-solid operations involving physical and chemical transformations such as 
drying, coating, granulation, combustion and gasification. This is because these beds combine features from both spouted and fluidized beds. In addition, an intense gas-solid mixing was observed leading to efficient heat and mass transfer. A detailed discussion regarding the distinguishing features of spout fluidized beds can be found in Epstein and Grace (2011) and Sutkar et al. (2013a). Moreover, these beds can be operated for coarse particles with wide size distributions. Since the development of the spout fluidized bed by Chatterjee (1970), a number of modifications were suggested to improve the bed performance. These modifications involve different geometrical configurations such as rectangular (Link et al., 2008), conical bottom (Zhong et al., 2006; Ren et al., 2011), slotted rectangular, multiple and elevated spout fluidized beds (van Buijtenen et al., 2011a, 2012). One of the significant modifications includes insertion of a draft tube inside the bed, which results in an improved performance by restricting the lateral particle flow. Moreover, insertion of a draft tube results in a stable spouting at lower flow rates, due to the reduced bypassing of the inlet gas (from spout to annulus). This is evident from the experimental study on spouted beds with and without draft tube by Ishikura et al. (2003). They observed a lower minimum spout velocity for a bed with a draft tube, which leads to lower energy consumption to achieve the similar spouting characteristics as in a system without a draft tube. Claflin and Fane (1983) imply that in a conventional spouted bed particles enter the spout from the annulus at various heights, leading to a random particle behavior. Furthermore, by using a draft tube, flexibility in the maximum spoutable height without disturbing the stable spouting can be successfully achieved. Additionally, the insertion of a draft tube in a spout fluidized bed provides an additional flexibility to control the particle velocity, bed porosity and gas residence time by adjusting operating parameters and geometrical configurations such as the entrainment height and the draft tube dimension.

A detailed understanding of the bed dynamics with flow transition is of primary importance for design and scale-up. This can be either achieved by performing experiments or simulations. However, it is troublesome to perform experiments on an industrial scale, because it is difficult to access the relevant areas experimentally. Over past few decades, the dynamics of gas-solid systems were studied using multiscale simulation approaches as reported by van der Hoef et al. (2008). For gas-solid contactor simulations were mainly performed using Eulerian-Lagrangian (the discrete model), the Eulerian-Eulerian approach (the continuum model), and hybrid Eulerian-Lagrangian approaches. In all the approaches the gas phase dynamics were described by the volume-averaged Navier-Stokes equations. In the Eulerian-Lagrangian approach the motion of the solids phase is obtained by solving Newton's law of motion for individual particle, whereas in the Eulerian-Eulerian approach the solid phase is considered as a continuum and particle-particle interactions were determined using a kinetic theory of granular flow (KTGF). The KTGF is also used to describe the particle-particle interactions in hybrid models (see e.g. Snider, 2001). The coupling of the KTGF with the Lagrangian framework is nontrivial however. There exist few studies on quantification of the hydrodynamic behavior of spout fluidized beds either by the Eulerian-Lagrangian or Eulerian-Eulerian approach. Link et al. (2004) performed simulations to study the hydrodynamics of a pseudo-2D spout fluidized bed $(W \times D \times$ $\left.H=0.15 \times 0.015 \times 1 \mathrm{~m}^{3}\right)$ using the discrete particle model $(\mathrm{DPM})$ and validated their results employing particle image velocimetry (PIV) and digital image analysis (DIA). Link et al. (2005) extended these studies to a 3D spout fluidized bed. Furthermore, Link et al. (2008) studied the flow characteristics in a 3D spout fluidized bed $(W \times D \times$ $H=0.15 \times 0.084 \times 1 \mathrm{~m}^{3}$, with spout dimension of $W \times D=0.022 \times$ $0.012 \mathrm{~m}^{2}$ ) using positron emission particle tracking (PEPT). They also studied a cylindrical spout fluidized bed $(D=0.4 \mathrm{~m})$ using a fiber optical probe (Link et al., 2009). Link et al. (2007) have reported DPM simulations of a pseudo-2D spout fluidized bed granulator with additional liquid injection. Deng et al. (2008) have developed a model to study the coal gasification in a pressurized 3D spout fluidized bed. Zhong et al. (2006) numerically studied the hydrodynamics in a rectangular spout fluidized bed using an Eulerian-Lagrangian approach. Zhong et al. (2007) have determined the flow patterns in a large scale spout fluidized bed $\left(D \times H=1 \times 6 \mathrm{~m}^{2}\right)$ at high pressure and temperature using an Eulerian-Eulerian approach. To model the gas phase dynamics a turbulence model was incorporated. Zhang et al. (2010) studied the particles mixing in a flat bottom spout fluidized bed using an Eulerian-Lagrangian approach, where the turbulence in the gas phase was modeled with a $k-\varepsilon$ model. van Buijtenen et al. (2009a) studied the effect of the inter-particle interactions on the spout fluidized bed dynamics, considering different values of the restitution coefficient. This study revealed that decrease in the restitution coefficient results in the formation of bubbles and causes more pronounced heterogeneity (instability) in the overall flow structure of the bed, which significantly depends on spout and background velocities. In addition, they have performed simulations extending the DPM to study the effect of inter-particle interaction with a variable restitution coefficient under wet conditions (with additional liquid injection, see van Buijtenen et al. (2009b)). Also, van Buijtenen et al. (2011b) performed experiments to analyze the effect of the collision properties using three particle types namely glass, $\gamma$ aluminum oxide and zeolite $4 \mathrm{~A}$ on dynamics of spout fluidized bed. During this study, variations in the solid volume fractions were analyzed using DIA.

Only very few simulation studies (Tsuji et al., 2008) were performed on industrial scale gas-solid contactors with a DPM involving huge numbers of particles due to the complexities in decomposing the results and the enormous computational time required. In this work, a scaling approach proposed by Link et al. (2009) has been used to simulate larger system by altering only physical properties of the gas and particle without including additional model equations. Even though simulation offers a platform that can be used to obtain better insight, it is necessary to validate the model prediction before they can be confidently applied for design and scaleup purposes. The efficacy of the developed model to predict the real system dynamics can be achieved by comparing model results with experimental data obtained with non-intrusive techniques. The experimental studies reported in the literature generally include determination of the particle velocity either by PIV or PEPT (Link et al., 2008) and solid volume fraction by DIA, X-ray tomography (Mudde, 2011) or electrical capacitance tomography (ECT) (van Buijtenen et al., 2012).

The main objective of this study is to numerically investigate the dynamics of a pseudo-2D spout fluidized bed with draft plates for two regimes viz. the spouting-with-aeration and fluidized bedspouting-with-aeration (dispersed spout) using a DPM. The obtained results are compared with experimental data that we obtained previously (Sutkar et al., 2013b). Also, an alternative simulation approach has been applied to reduce the total computational time for a large gas-solid system based on a method suggested by Link et al. (2009). The obtained results were compared with an experimental data, as well as with simulations with the original parameters.

\section{Numerical investigations}

\subsection{Model equations}

The model equations (Eqs. (1)-(8)) used in this work are summarized in Table 1 . The gas phase dynamics were determined by solving the volume-averaged Navier-Stokes equations (Eqs. (1) 
Table 1

Model equations used for numerical investigations of a spout fluidized bed.

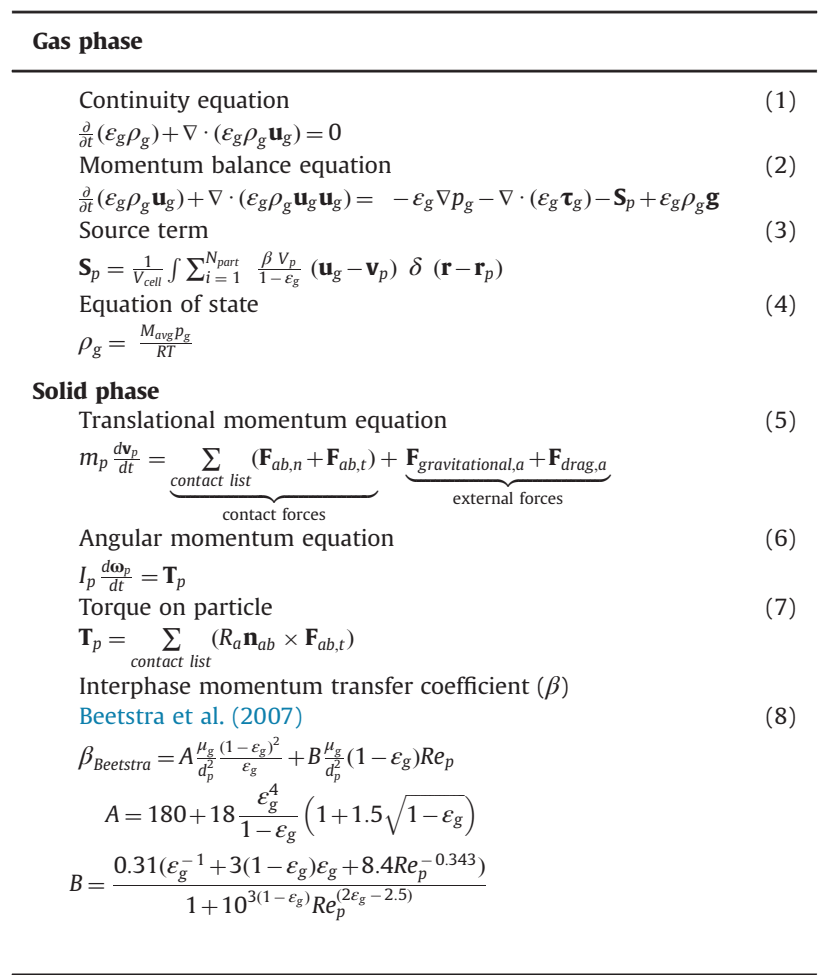

and (2)), whereas the motion of the particles was determined by solving the equations of motion (Eqs. (5)-(7)).

The turbulence generated due to high velocity spout was modeled using the sub-grid scale (SGS) turbulence model proposed by Vreman (2004). This model can handle both transitional and wall-bounded turbulent flows. Also, this model does not involve explicit filtering, averaging or other clipping procedures. The shear induced turbulent viscosity in this model is given by

$\mu_{t u r}=c \rho_{g} \sqrt{\frac{B_{\beta}}{\alpha_{i j} \alpha_{i j}}}=2.5 C_{S}^{2} \rho_{g} \sqrt{\frac{B_{\beta}}{\alpha_{i j} \alpha_{i j}}}$

$B_{\beta}=\beta_{11} \beta_{22}-\beta_{12}^{2}+\beta_{11} \beta_{33}-\beta_{13}^{2}+\beta_{22} \beta_{33}-\beta_{23}^{2}$

$\beta_{i j}=\Delta_{m}^{2} \alpha_{m i} \alpha_{m j}$

$\alpha_{i j}=\partial_{i} \mathbf{u}_{j}=\frac{\partial \mathbf{u}_{j}}{\partial x_{i}}$

here $\Delta_{m}$ is the local filter width. The model constant $c$ is related to the Smagorinsky constant $C_{S}$ (Smagorinsky, 1963) by $c \approx 2.5 C_{S}^{2}$. The symbol $\alpha$ stands for the $(3 \times 3)$ matrix of the derivatives of the filtered velocity $\mathbf{u}_{g}$.

\subsection{Inter-phase coupling and internal wall treatment}

The inter-phase momentum transfer between gas and solid phases was determined using an appropriate mapping function. A smooth transfer of properties between the Eulerian gird and Lagrangian positions can be achieved through mapping functions as described in more detail by Deen et al. (2004) and Link (2006). Unlike other mapping functions the mapping function proposed by Link (2006) performs mapping over a cubic volume (with a mapping window diameter of 5 times the particle diameter) irrespective of the grid size. This function facilitates smooth momentum transfer independent of grid size.

In this study, the simulations were carried out considering an approach originally proposed by Link (2006). In this approach, each particle is represented by a porous cube, with a size equal to $d_{\text {cube }}=d_{p} a$, where ' $a$ ' is the ratio of cube diameter to particle diameter. The cube porosity can be calculated from

$\varepsilon_{\text {cube }}=\frac{V_{p}}{V_{\text {cube }}}=\frac{\pi}{6 a^{3}}$

In general, variables from the Eulerian grid $\left(\phi_{E}\right)$ are mapped to the Lagrangian positions $\left(\phi_{L}\right)$ and vice versa using

$\phi_{E}=V_{\text {cell }} \sum_{\forall j \in \text { cell }} \frac{f_{\text {cell }}^{i} \phi_{L}}{V_{i}}$

$\phi_{L}=\frac{1}{V_{\text {cube }}} \sum_{\forall j \in \text { cube }} f_{j}^{\text {cube }} V_{j} \phi_{E}$

where $f_{j}^{\text {cube }}$ is the volume fraction of cell $j$ occupied by the cube and $f_{\text {cell }}^{i}$ is the volume fraction of cell $i$ occupied by the cube. For particles close to a wall the mapping function is folded back into the simulation domain, as illustrated in Fig. 1. For the simulation of a spout fluidized bed with draft plates, a similar approach as proposed by Link (2006) has been applied for the internal walls. However, cells in the vicinity of corners of internal walls are folded around both walls, as illustrated in Fig. 2 .

Internal walls inside the bed are defined using a flag matrix concept, which offers the flexibility to define different boundary conditions by assigning a specific value to the cell flag. These cell flags are associated with relevant information about the boundary condition. More information about the flag matrix concept can be found in Hoomans et al. (1996).

In this simulation, no-slip boundary conditions were defined for internal walls by setting the tangential velocity of fictitious (wall) cells equal to the tangential velocity of internal (fluid) cells wall, however with an opposite sign. Furthermore, collisions between the particles and an internal wall were treated in the same manner as those with external walls. Particles collisions on a corner of an internal wall were treated on the basis of the particle 


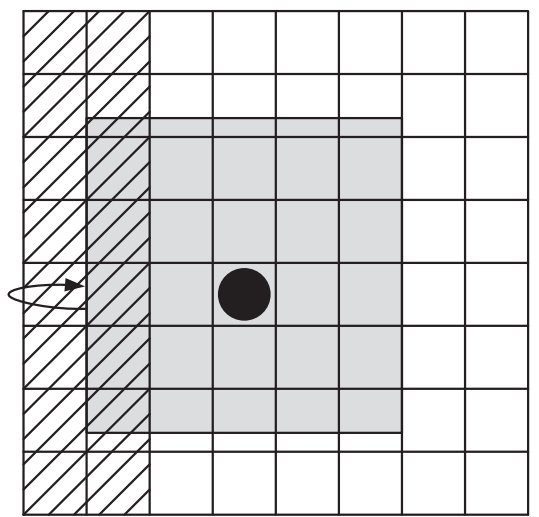

Regular mapping cube

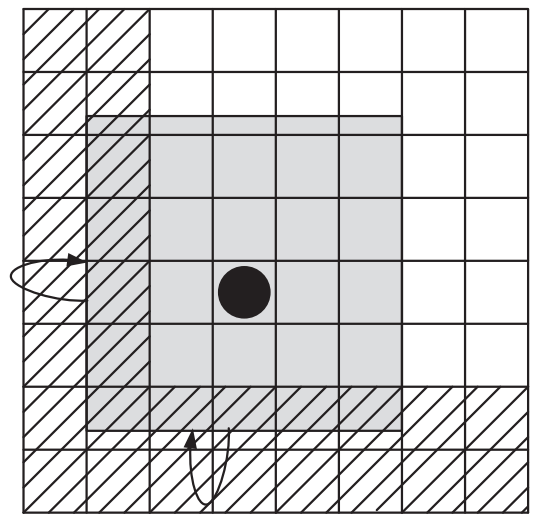

Regular mapping cube

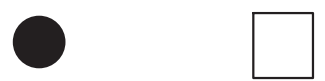

Particle

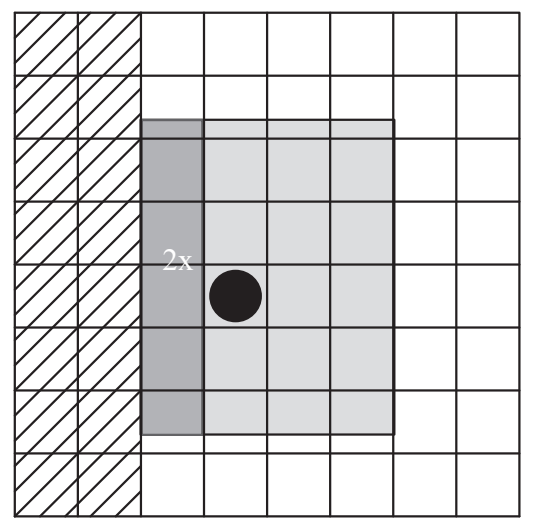

Folded mapping cube

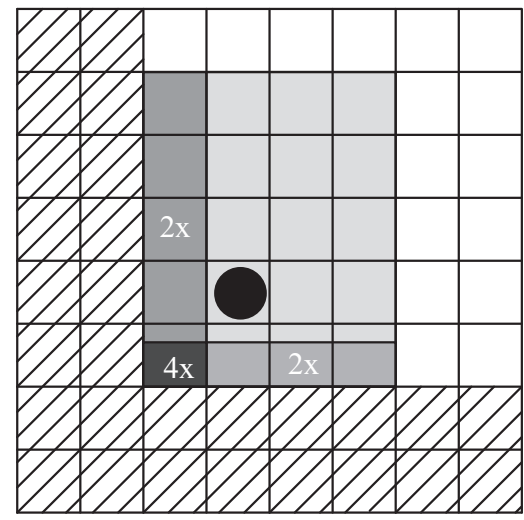

Folded mapping cube

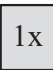

$1 x$

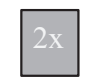

$4 \mathrm{x}$

Weighing factor

Fig. 1. Representation of the mapping window at the boundaries of the computational domain.

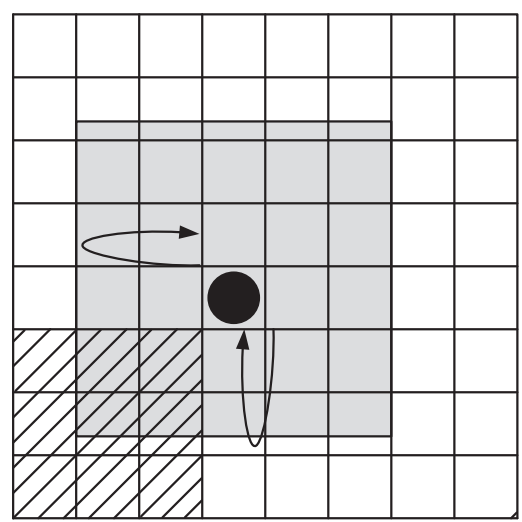

Regular mapping cube

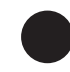

Particle

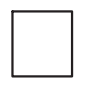

Flow cell

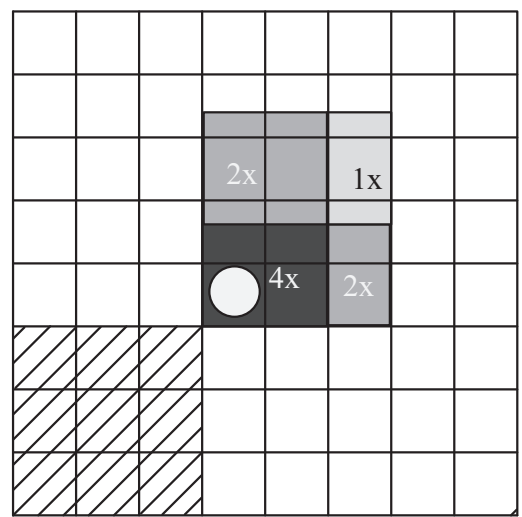

Folded mapping cube
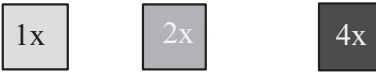

Weighing factor

Fig. 2. Representation of the mapping window near the corner of an internal wall.

center of mass, as illustrated in Fig. 3. A particle with its center of mass below the diagonal line will collide with the side surface of the wall, whereas a particle with its center of mass above the diagonal line will collide with the top surface.
An overview of the various boundary conditions used in DPM simulations can be found in Table 2. In this study the simulations were performed by applying the no-slip conditions at the side walls, whereas the bottom wall was set as an inflow boundary. The 


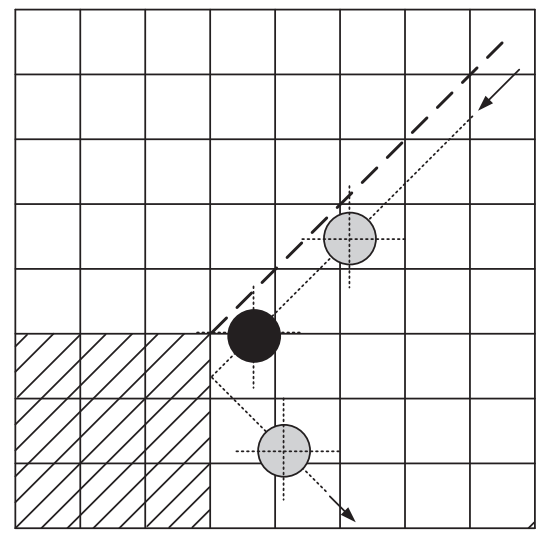

Collsion of particle on side surface

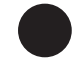

Particle

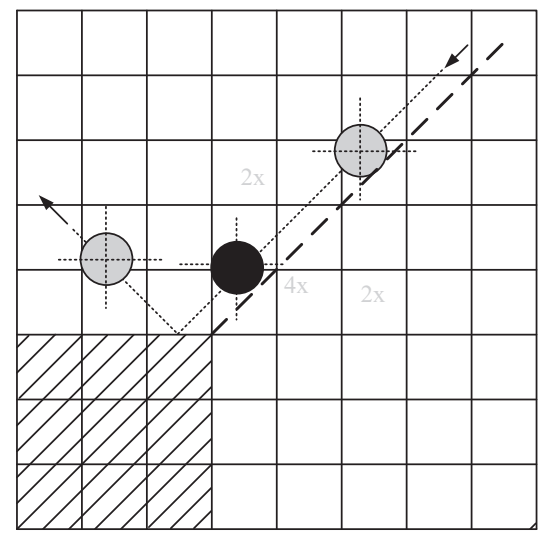

Collision of particle on top surface

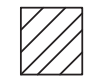

Wall cell

Fig. 3. Representation of a particle collision with an internal wall, on treatment of a 'near-comer' collision based on the particle center of mass.

Table 2

Cell flag values for the boundary conditions.

\begin{tabular}{ll}
\hline $\mathbf{F l}(\boldsymbol{i}, \boldsymbol{j}, \boldsymbol{k})$ & Type of Cell \\
\hline 1 & Interior cell, no boundary conditions to be specified \\
2 & Symmetry boundary condition, free slip boundaries \\
3 & Impermeable wall, no-slip boundaries \\
4 & Fluid phase influx cell, velocities have to be specified \\
5 & Prescribed pressure cell, free slip boundaries \\
6 & Continuous outflow cell, free slip boundaries \\
7 & Corner cell, no boundary conditions have to be specified \\
8 & Internal wall, no slip boundaries \\
\hline
\end{tabular}

draft plates were modeled as internal walls with no-slip conditions. Fig. 4 illustrates the boundary conditions used in our simulations.

\subsection{Scaling approach}

Large scale gas-solid contactors may contain billions of particles, involving an even greater number of mutual collisions. To predict dense gas-solid flows in such large systems enormous computational efforts are required. This issue can be handled by a parallel computing, in which the simulations are carried out on a large parallel processor. Up till now, Tsuji et al. (2008) have performed DPM simulations for a large fluidized bed of dimensions $D \times W \times H=1.2 \times 1.2 \times 0.8 \mathrm{~m}^{3}$ with 4.5 million particles $\left(d_{p}=4 \mathrm{~mm}\right.$ and $\left.\rho_{p}=2700 \mathrm{~kg} / \mathrm{m}^{3}\right)$ using 16 central processing units and revealed that it is cumbersome to decompose a large simulation into a number of smaller simulations. Alternatively, several models were proposed for simulating large numbers of particles. Kazari et al. (1995) developed a model to simulate the motion of particles without significant agreement in quantification of the pressure drop and bubble behavior. Sakano and Yaso (2000) proposed a model, by considering an imaginary particle with larger diameter and smaller density (same $u_{m f}$ ). Their results reveal differences between experimental and simulated bubble diameter. Sakai et al. (2010) proposed a coarse-grained model to simulate the larger particulate system using DPM. In this model, a collection of particles were indirectly represented by a set of representative particles. This leads to dramatic reduction in the total particles retaining similar bed characteristics. In a similar

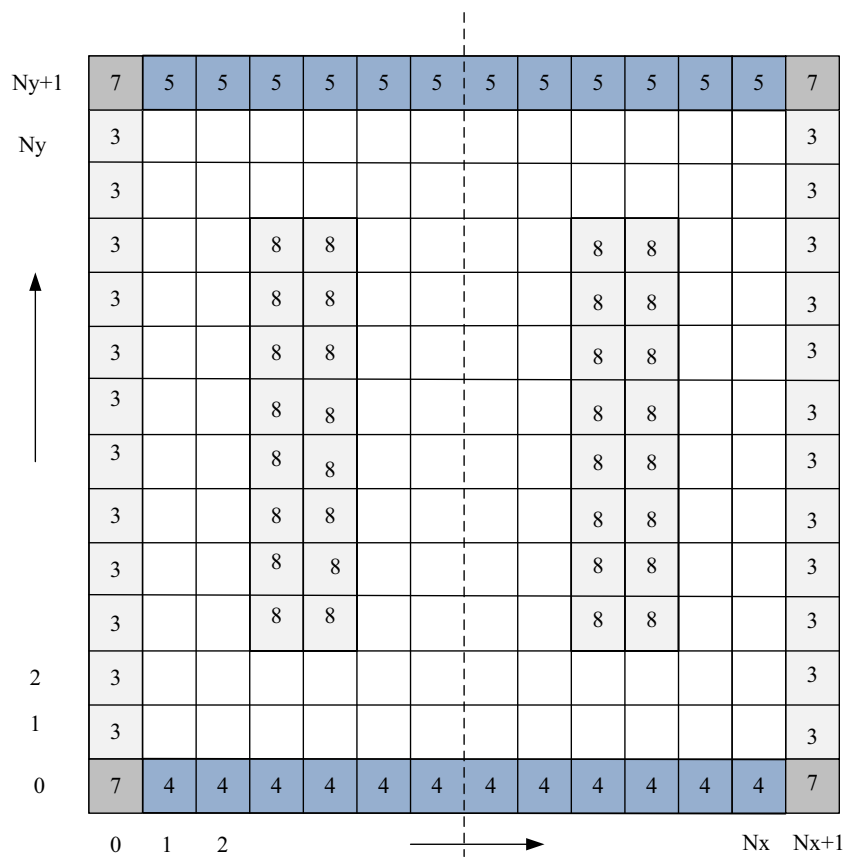

Fig. 4. Boundary condition representation using flag matrix concept.

way, Mokhtar et al. (2012) proposed a similar particle assembly (SPA) model by considering Geldart A and D particles and reported good agreement with experimental findings.

In this work, a scaling approach proposed by Link et al. (2009) has been used, in which the scaling of the particle was performed by keeping constant Archimedes number (Ar, ratio of gravity and inertial forces) and the particle Reynolds number (Re, ratio of inertial and viscous forces). This approach considerably reduces the particles in gas-solid systems to mitigate the total computational time. This study was performed by keeping constant particle volume with a reduced particles, that is, by increasing the particle diameter with a factor $k$. In this way the number of particles in the system gets reduced by a factor of $k^{3}$. The overall change in particle size can be balanced by changing the physical properties of the gas and solid phases, while ensuring constant Archimedes number, 
a

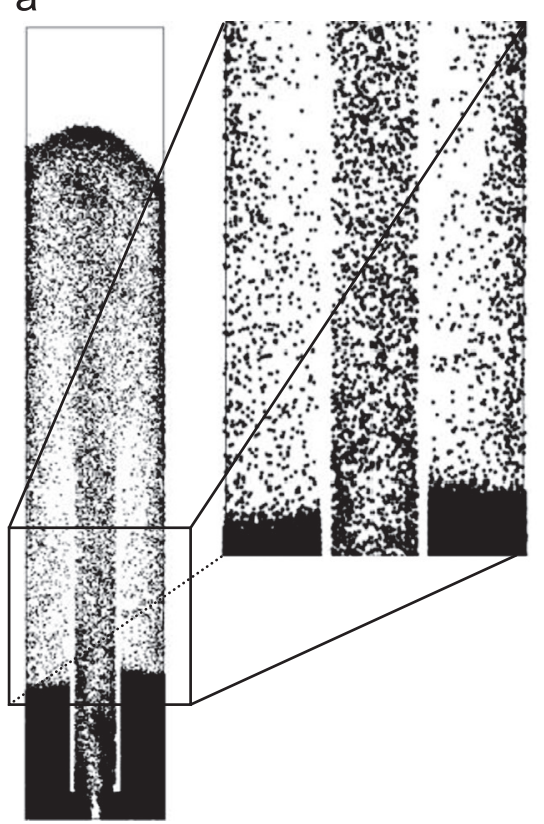

b

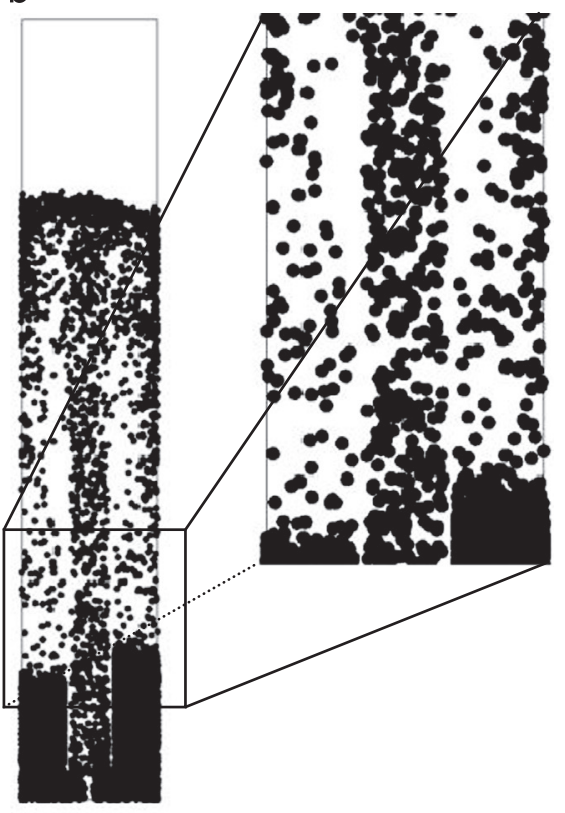

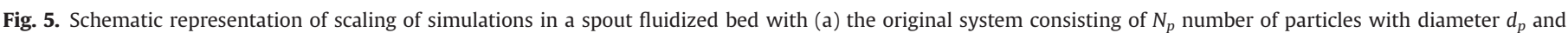
density $\rho_{p}$ and (b) the scaled system consisting of $\left(N_{p} / k^{3}\right)$ number of particles of diameter $\left(k d_{p}\right)$ and density of $\left(\rho_{p} / k\right)$, where $k$ is the scaling factor.

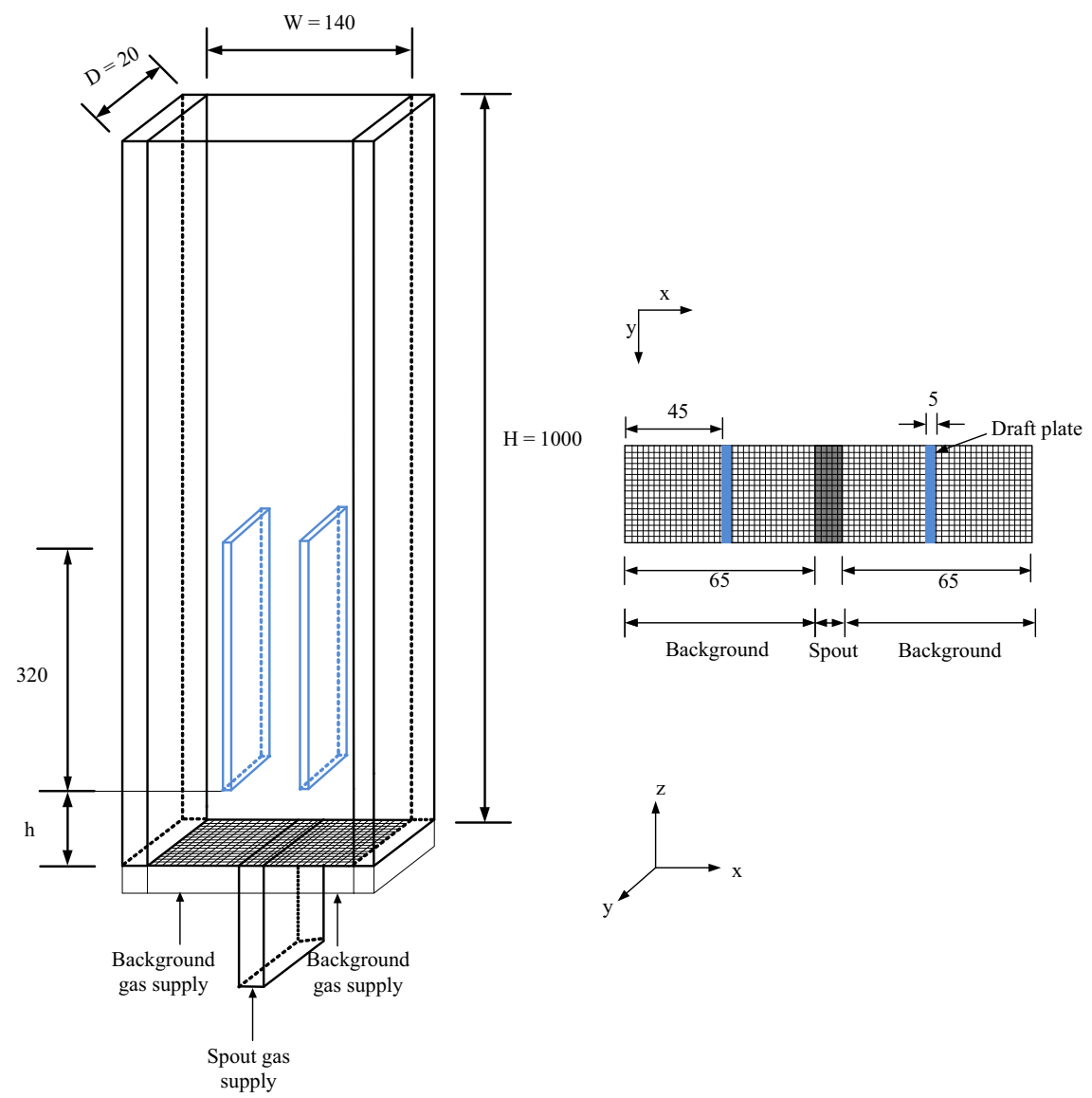

Fig. 6. Schematic representation of a pseudo-2D spout fluidized bed with draft plates (all dimensions in $\mathrm{mm}$ ).

Reynolds number, minimum fluidization velocity $\left(u_{m f}\right)$ and the bed porosity $\left(\varepsilon_{s}\right)$. More details of this scaling procedure are given in Appendix A (Eqs. (A1)-(A5)). A typical example of an unscaled (simulation with 461,443 particles) and a scaled (simulation with
57,681 particles) system is given in Fig. 5. Note that, scaled simulations were performed by changing only the number, the diameter and the density of particles while keeping the other simulation settings the same. 
Table 3

Investigated flow regimes and particle types.

\begin{tabular}{lll}
\hline Case & Description & Particles \\
\hline B1 & Spouting-with-aeration & Glass \\
B2 & Fluidized bed-spouting-with-aeration (dispersed spout) & Glass \\
B3 & Spouting-with-aeration & $\gamma$-Aluminum oxide \\
B4 & Fluidized bed-spouting-with-aeration (dispersed spout) & $\gamma$-Aluminum oxide \\
L1 & Spouting-with-aeration & glass \\
L2 & Spouting-with-aeration & $\gamma$-Aluminum oxide \\
\hline
\end{tabular}

Table 4

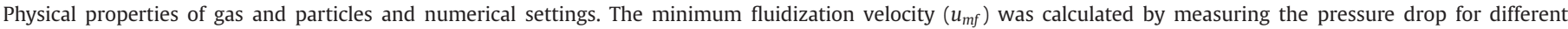

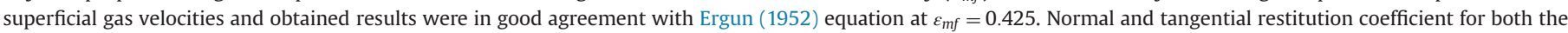

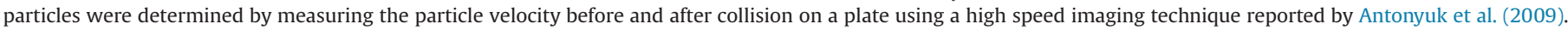

\begin{tabular}{|c|c|c|c|c|c|c|c|}
\hline Parameters/case & B1 & B2 & B3 & B4 & L1 & $\mathbf{L 2}$ & Unit \\
\hline Material & Glass & Glass & $\gamma$-Aluminum oxide & $\gamma$-Aluminum oxide & Glass & $\gamma$-aluminum oxide & - \\
\hline$d_{p}$ & 1 & 1 & 1 & 1 & 2 & 2 & $\mathrm{~mm}$ \\
\hline$\rho_{p}$ & 2526 & 2526 & 1040 & 1040 & 1263.6 & 520.6 & $\mathrm{~kg} / \mathrm{m}^{3}$ \\
\hline$e_{n, p \leftrightarrow p}$ & 0.97 & 0.97 & 0.74 & 0.74 & 0.97 & 0.74 & - \\
\hline$e_{n, p \leftrightarrow w}$ & 0.97 & 0.97 & 0.74 & 0.74 & 0.97 & 0.74 & - \\
\hline$e_{t, p \leftrightarrow p}$ & 0.33 & 0.33 & 0.1 & 0.1 & 0.33 & 0.1 & - \\
\hline$e_{t, p \leftrightarrow w}$ & 0.33 & 0.33 & 0.1 & 0.1 & 0.33 & 0.1 & - \\
\hline$\mu_{p \leftrightarrow p}$ & 0.1 & 0.1 & 0.1 & 0.1 & 0.1 & 0.1 & - \\
\hline$\mu_{p \leftrightarrow w}$ & 0.1 & 0.1 & 0.1 & 0.1 & 0.1 & 0.1 & - \\
\hline$N_{p}$ & 461,443 & 461,443 & 461,443 & 461,443 & 57,681 & 57,681 & - \\
\hline$u_{b g}$ & 0.32 & 0.81 & 0.17 & 0.43 & 0.32 & 0.17 & $\mathrm{~m} / \mathrm{s}$ \\
\hline$u_{b g} / u_{m f}$ & 0.5 & 1.275 & 0.5 & 1.275 & 0.5 & 0.5 & - \\
\hline$u_{s p}$ & 28.4 & 23.5 & 15.08 & 12.5 & 28.4 & 15.08 & $\mathrm{~m} / \mathrm{s}$ \\
\hline$u_{s p} / u_{m f}$ & 44.37 & 37.00 & 44.37 & 37.00 & 44.37 & 44.37 & - \\
\hline$\rho_{g}$ & 1.2 & 1.2 & 1.2 & 1.2 & 1.2 & 1.2 & $\mathrm{~kg} / \mathrm{m}^{3}$ \\
\hline$\mu_{g}$ & $1.8 \times 10^{-5}$ & $1.8 \times 10^{-5}$ & $1.8 \times 10^{-5}$ & $1.8 \times 10^{-5}$ & $3.6 \times 10^{-5}$ & $3.6 \times 10^{-5}$ & $\mathrm{~kg} / \mathrm{m} \mathrm{s}$ \\
\hline$k$ & 1 & 1 & 1 & 1 & 2 & 2 & - \\
\hline
\end{tabular}

Table 5

Numerical settings used for the DPM simulations.

\begin{tabular}{lll}
\hline Parameter & Value & Unit \\
\hline$\Delta x, \Delta y, \Delta z$ & $2.5 \times 10^{-3}$ & $\mathrm{~m}$ \\
$\Delta t_{g}$ & $1.5 \times 10^{-5}$ & $\mathrm{~s}$ \\
$\Delta t_{p}$ & $3 \times 10^{-6}$ & $\mathrm{~s}$ \\
$k_{n}$ & $1.1 \times 10^{4}$ & $\mathrm{~N} / \mathrm{m}$ \\
$k_{t}$ & 3142.8 & $\mathrm{~N} / \mathrm{m}$ \\
\hline
\end{tabular}

\section{Test cases}

Simulations were carried out for a pseudo-2D spout fluidized bed, shown in Fig. 6, of the dimensions $W \times D \times H=0.14 \times$ $0.02 \times 1 \mathrm{~m}^{3}$ with the spout of $W_{s p} \times D_{s p}=0.01 \times 0.02 \mathrm{~m}^{2}$. Two symmetrical draft plates each of dimension $W_{d t} \times D_{d t} \times$ $H_{d t}=0.005 \times 0.02 \times 0.32 \mathrm{~m}^{3}$ were positioned inside the bed at a distance of $0.045 \mathrm{~m}$ from the side walls and at an entrainment height $h=0.03 \mathrm{~m}$ from the bottom. The bed was initially filled to a height $H_{0}=W=0.14 \mathrm{~m}$

In addition to scaling, the further objective of this work is to study the effect of the draft plates and physical properties of the particles on the bed dynamics using a DPM with a soft-sphere collision model. Several simulations were conducted by varying the spout and background velocities, geometrical configuration and physical properties of the particles are summarized in Tables 3 and 4 . Cases B1-4 were performed using the original system parameters, whereas in cases L1 and L2 the scaled parameters were used. The numerical settings used in the DPM simulations are listed in Table 5.

\section{Results and discussion}

The prevailing flow patterns not only depend on the geometrical configuration, but also on the particle physical properties. To this end, we investigated the effect of two particle materials with different properties. In this section, the results for the spouting-with-aeration regime and the fluidized bed-spouting-with-aeration (dispersed spout) regime are presented, both for glass and $\gamma$-aluminum oxide particles. It is noted that the simulations for the two particle types were carried by keeping $u_{s p} / u_{m f}$ and $u_{b g} / u_{m f}$ constant. The simulation results are compared with the experimental data and results obtained from simulations with the scaled parameters. In the scaled simulations, particle diameters of glass and $\gamma$-aluminum oxide particles were changed from $1 \mathrm{~mm}$ to $2 \mathrm{~mm}$, whereas the particle densities were reduced to 1263.6 and $520.6 \mathrm{~kg} / \mathrm{m}^{3}$, for glass and $\gamma$-aluminum oxide particle respectively. As a result, the total number of particles is reduced by a factor of $2^{3}$.

In this section, variation in the flow patterns will be discussed and the obtained results are compared with previous experiments of Sutkar et al. (2013b). In these experiments high speed images were captured with a small time interval, which are utilized for identifying the flow patterns, particle velocity and volume fraction distributions. In PIV, two subsequent images with a small time interval $(\Delta t)$ were captured and subdivided into interrogation areas based image resolution and cross-correlation was applied to 

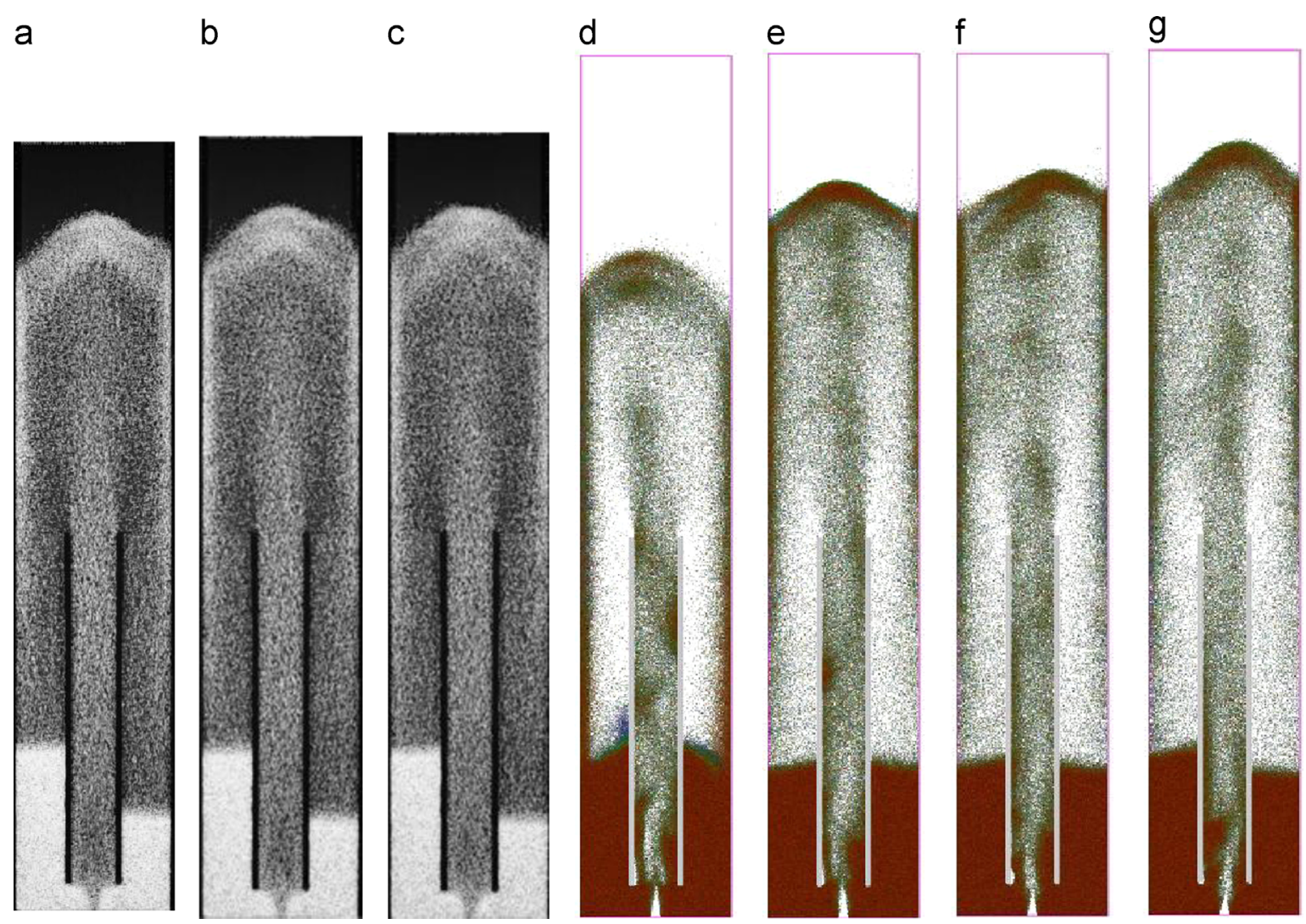

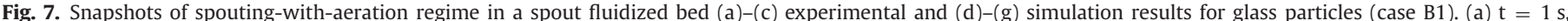
(b) $\mathrm{t}=2.5 \mathrm{~s}$, (c) $\mathrm{t}=3.5 \mathrm{~s}$, (d) $\mathrm{t}=1 \mathrm{~s}$, (e) $\mathrm{t}=2 \mathrm{~s}$, (f) $\mathrm{t}=3 \mathrm{~s}$, (g) $\mathrm{t}=7.5 \mathrm{~s}$.

a

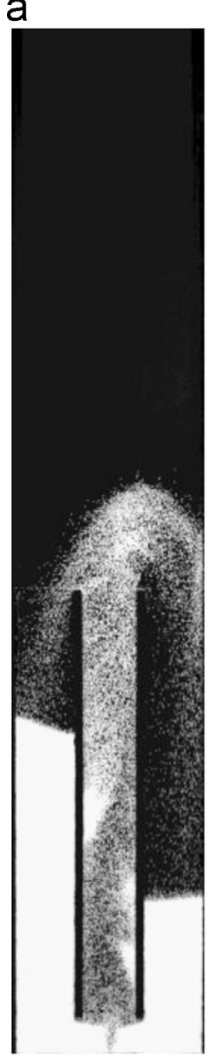

b

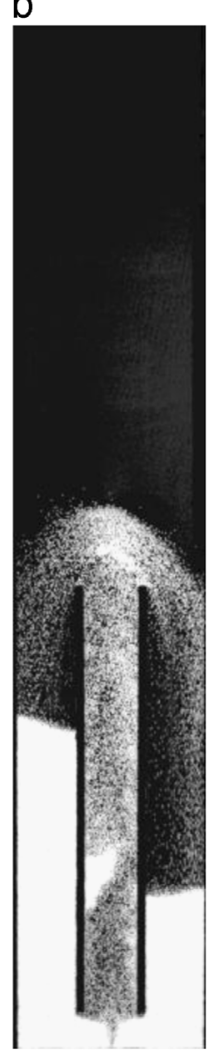

c

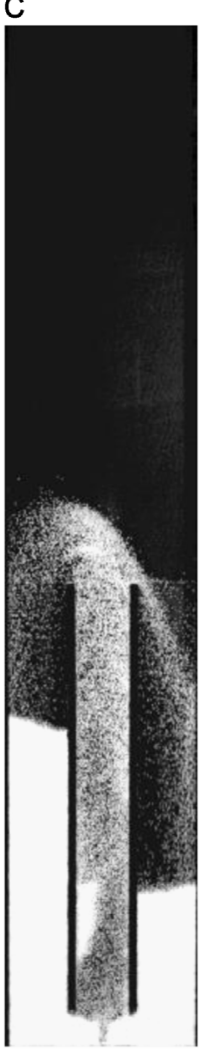

d

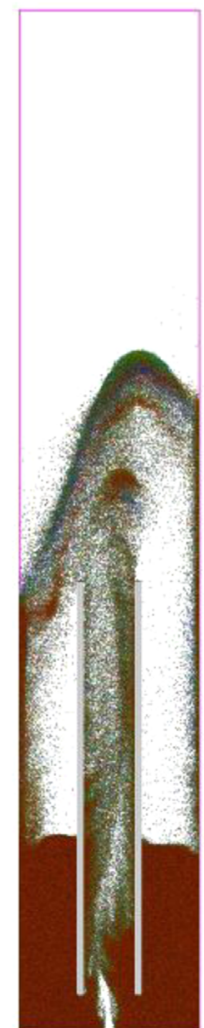

e

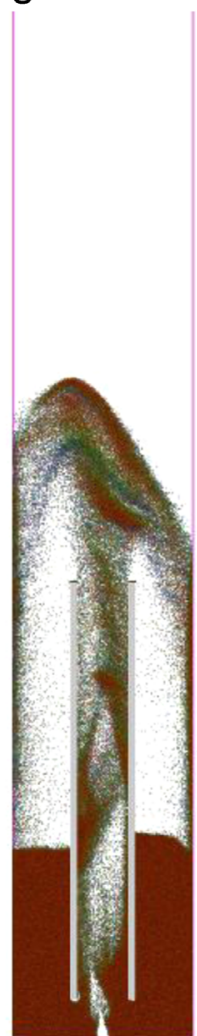

f

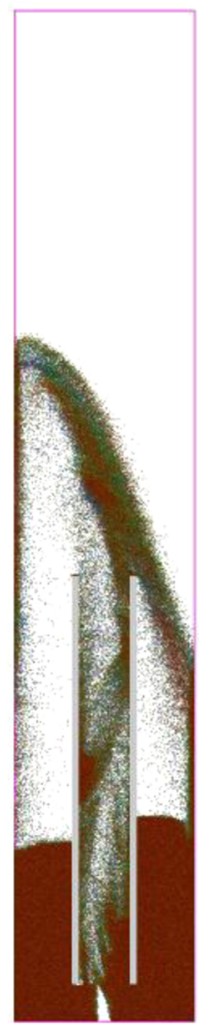

g

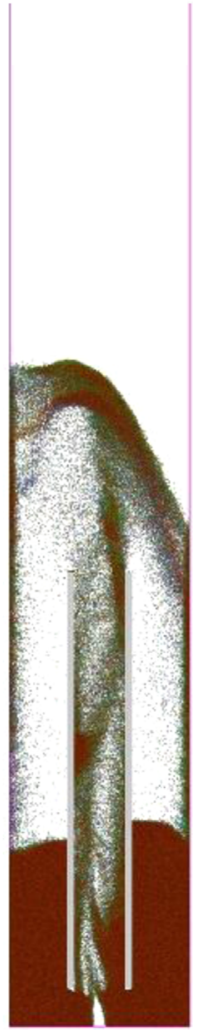

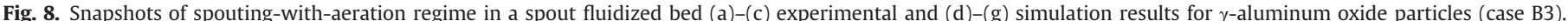
(a) $\mathrm{t}=1 \mathrm{~s}$, (b) $\mathrm{t}=2.5 \mathrm{~s}$, (c) $\mathrm{t}=3.5 \mathrm{~s}$, (d) $\mathrm{t}=1 \mathrm{~s}$, (e) $\mathrm{t}=2 \mathrm{~s}$, (f) $\mathrm{t}=3 \mathrm{~s}$, (g) $\mathrm{t}=7.5 \mathrm{~s}$. 
a

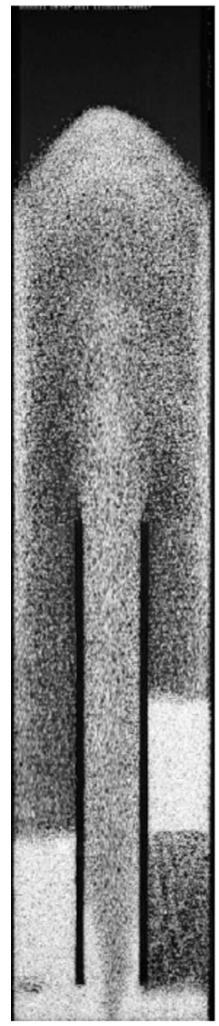

b

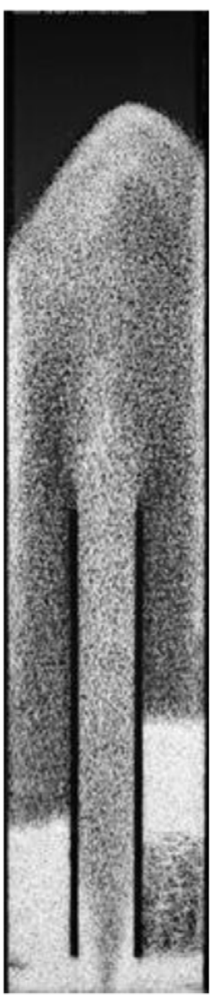

C

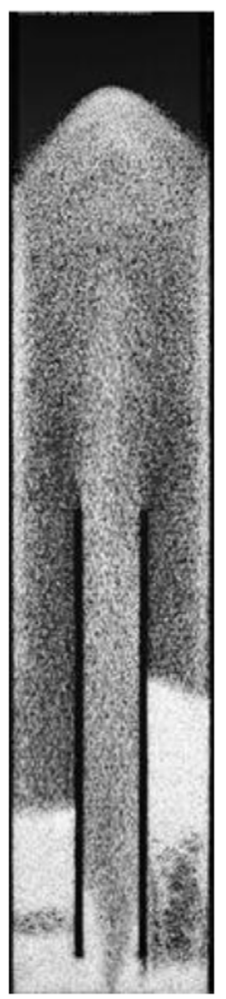

d

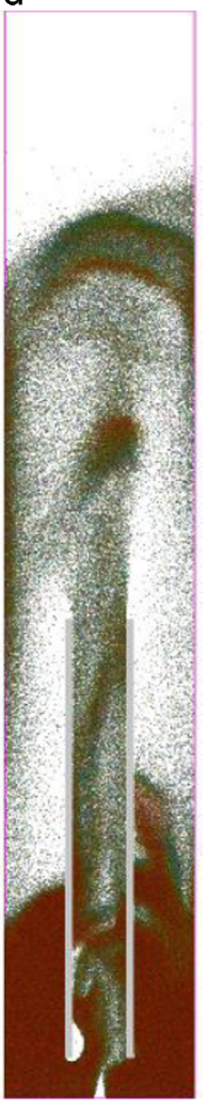

e

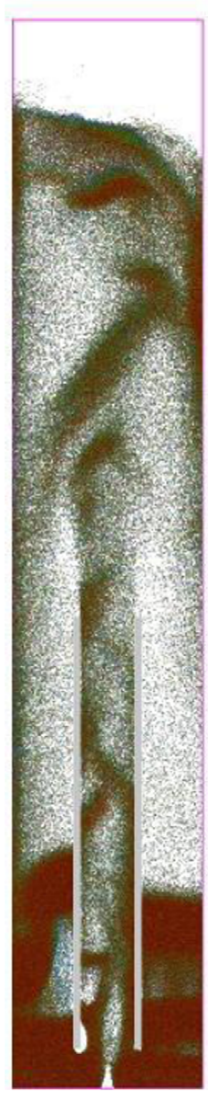

$f$

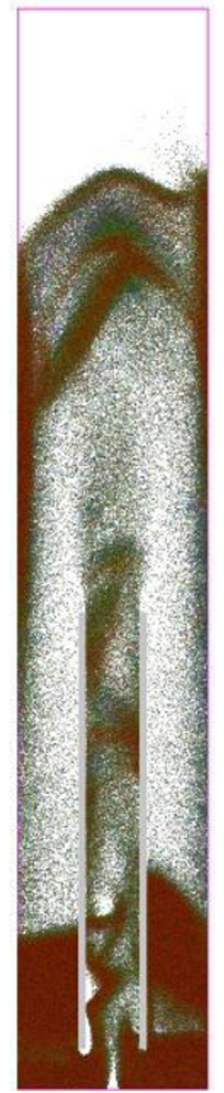

9

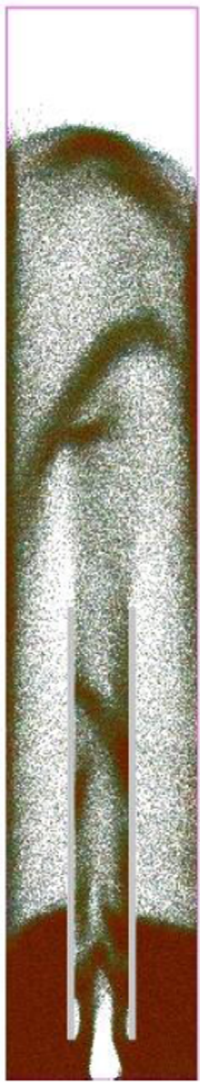

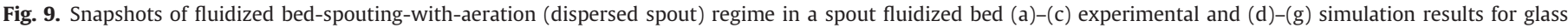
particles (case B2). (a) $\mathrm{t}=1 \mathrm{~s}$, (b) $\mathrm{t}=2.5 \mathrm{~s}$, (c) $\mathrm{t}=3.5 \mathrm{~s}$, (d) $\mathrm{t}=1 \mathrm{~s}$, (e) $\mathrm{t}=2 \mathrm{~s}$, (f) $\mathrm{t}=3 \mathrm{~s}$, (g) $\mathrm{t}=7.5 \mathrm{~s}$.

determine the volume average particle displacement $\left(\mathbf{s}_{p}\right)$. The particle velocity in each interrogation area is determined by

$\mathbf{v}_{p}(\mathbf{x}, t)=\frac{\mathbf{s}_{p}}{M \Delta t}$

where $M$ is the image magnification factor and $\Delta t$ the time interval, which is maintained sufficiently small. During recording, $\Delta t=1 \mathrm{~ms}$ was used and image pairs were recorded at $10 \mathrm{~Hz}$ frequency. Digital image analysis (DIA) was also used to discriminate the gas and solids phase by allocating the highest intensity to the solids phase and the lowest to the gas phase using a similar approach as reported by van Buijtenen et al. (2011b). The timeaveraged particle velocities in the vertical direction $\left(\left\langle\boldsymbol{v}_{p, z}\right\rangle\right)$ and the associated volumetric fluxes $\left(\left\langle\Phi_{p, z}\right\rangle\right)$ were quantified at various heights and compared with experimental data.

\subsection{Spouting-with-aeration}

In this regime, a stable spouting was observed in the spout with a random particle movement in the annulus, which can be seen from Figs. 7 and 8 respectively for the glass and $\gamma$-aluminum oxide particles. With increasing a spout velocity, the particles in the spout, after reaching the zone above the draft plates move in the lateral direction, lose their momentum and fall down in the annulus. The extended discussion about the particulate flow for glass and $\gamma$-aluminum oxide particles is given in the following section.

\subsubsection{Glass particles (B1)}

With increasing a spout velocity, particles near the distributor plate are accelerated upwards through the draft plates to a certain height, without pronounced clusters. After reaching a certain height, particles move laterally and subsequently lose their momentum and move down into the annulus. This continuous upward and downward transport of the particles leads to a steady particle circulation pattern, with relatively high particle velocities inside the draft plates. Fig. 7(a)-(c) shows images from experiment for the spouting-with-aeration regime, illustrating non-uniform particle distribution between the left and right compartments of the bed. This non-uniformity primarily depends on the extent of gas bypassing during the experiments, initial amount of particles in the annulus and generation of the spout. During the experiments, it was observed that the gas emerging from the spout frequently diverted towards the right side withdrawing and transporting a larger number of particles from the right annulus section.

Similar circulatory behavior was observed during simulations (which can be seen from the images shown in Fig. 7(d)-(g)). However, during the simulations more homogenous particle distributions were observed in the annulus (up to $t=3 \mathrm{~s}$ ) as compared with the experiments. This is because the particles near the distributor plate offers a uniform static load on incoming gas, without any deviation in the spout. But, after reaching a quasisteady condition (at simulation time $t=7.5 \mathrm{~s}$ ) non-uniformity in the particle distribution can be clearly seen from Fig. $7(\mathrm{~g})$.

\subsection{2. $\gamma$-Aluminum oxide particle (B3)}

Furthermore, simulations were carried for $\gamma$-aluminum oxide particles, for which similar circulation patterns were observed as those for glass particles. Fig. 8(a)-(c) and (d)-(g) shows snapshots obtained from the experiment and the simulation respectively, 
illustrating the particle clusters inside the draft plates which lead to spout meandering inside the draft plates. Also, $\gamma$-aluminum oxide particles were transported to a lower height compared to glass particles, despite of the same $u_{s p} / u_{m f}$ and $u_{b g} / u_{m f}$. This is due to the differences in the particle physical properties especially the restitution coefficient. The particles with a lower restitution coefficient promote the formation of dense regions mainly in the form of clusters with pronounced energy dissipation during particle-particle collisions. In this regime, the spout velocity was not sufficient to lift the formed particle clusters. Hence, the periodic formation and collapse of the particles clusters was observed inside the draft plates. This leads to a lower exchange rate of particles between the zone inside the draft plates and the annulus. In addition, the formed clusters partially block the draft plates encouraging unsteady pulsating particulate flow patterns with a reduced bed height. In the simulations, an equal particle distribution on both sides of the draft plates was observed, which is in contrast with the experimental observations.

\subsection{Fluidized bed-spouting-with-aeration (dispersed spout)}

In the fluidized bed-spouting-with-aeration (dispersed spout) regime, the particles in the draft plates were elevated to a higher height as compared with the spouting-with-aeration regime, due to the higher background velocities with considerable particle displacement in the annulus. The total system operates like a circulating bed. Snapshots obtained from the experiments and simulations are shown in Figs. 9 and 10 for glass and $\gamma$-aluminum oxide particles respectively.

\subsubsection{Glass particles (B2)}

Fig. 9(d)-(g) displays a series of snapshots obtained from simulations for the fluidized bed-spouting-with-aeration regime using glass particles. Both simulation and experiments show the slug formation in the annulus due to high background velocity and narrow annulus. Contrary to the experiments in the simulation the formation of particle clusters inside the draft plates is observed. These clusters partially block the draft plates and induce an unsteady pulsating flow with varying bed height. Furthermore, bubble formation was also observed in the annulus. Bubbles often propagate through the annulus in the form of slugs, due to the small width of the annulus. It is generally assumed that, the generation of slugs commences when the bubble size approaches $2 / 3$ of the bed width. It should be also noted that the particle circulation attributes to particle leaking from the bottom of the slugs in the downward direction.

\subsection{2. $\gamma$-Aluminum oxide particles (B4)}

The simulation results for $\gamma$-aluminum oxide particles are depicted in Fig. 10(d)-(g). It is observed that $\gamma$-aluminum oxide particles are transported to a lower height compared to glass particles. Moreover, a high particle concentration zone was observed above the draft plates. Note that, $\gamma$-aluminum oxide particles show cone like structure as compared to the glass particles. Furthermore, despite the higher background velocity, less pronounced particle movement was observed in the annulus with an unstable spout. This may be due to the change in the physical properties of the particles, especially the restitution coefficient. At low restitution coefficient a higher amount of energy is dissipated during inter-particle collisions, leading to a

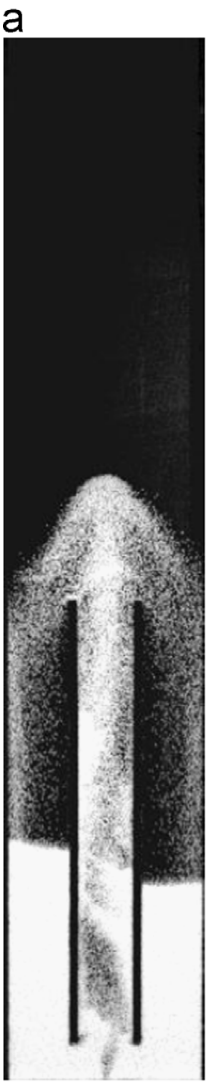

b

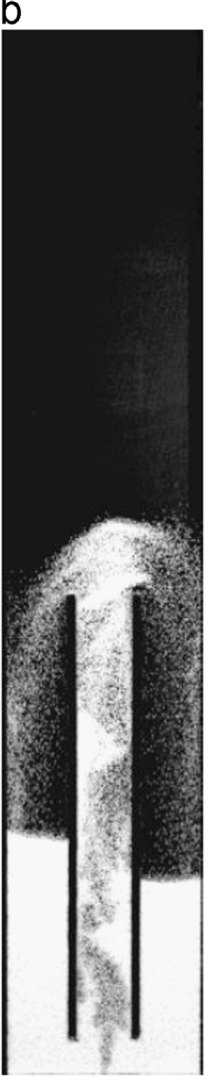

C

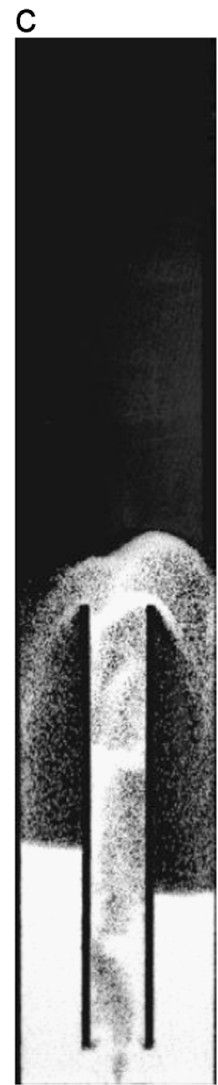

d

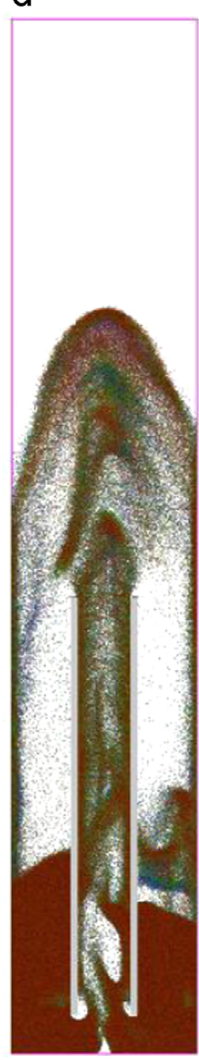

e

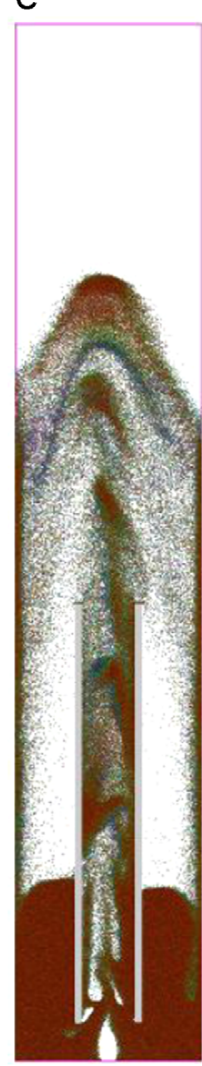

f

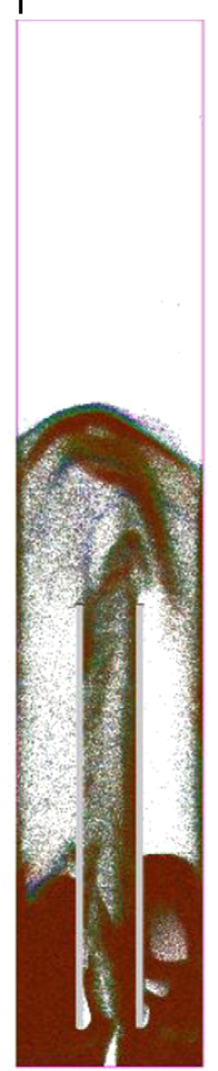

g

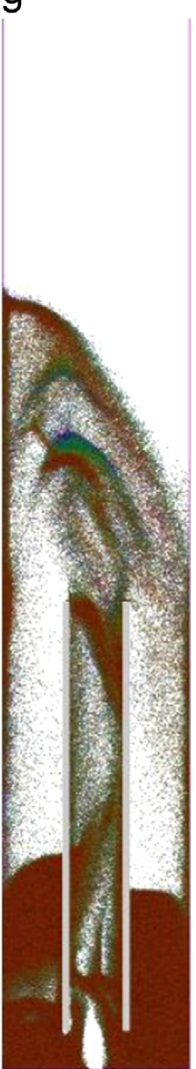

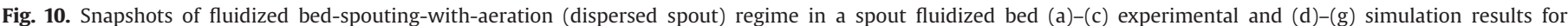
$\gamma$-aluminum oxide particles (case B4). (a) $t=1 \mathrm{~s}$, (b) $t=2.5 \mathrm{~s}$, (c) $\mathrm{t}=3.5 \mathrm{~s}$, (d) $\mathrm{t}=1 \mathrm{~s}$, (e) $\mathrm{t}=2 \mathrm{~s}$, (f) $\mathrm{t}=3 \mathrm{~s}$, (g) $\mathrm{t}=7.5 \mathrm{~s}$. 
a

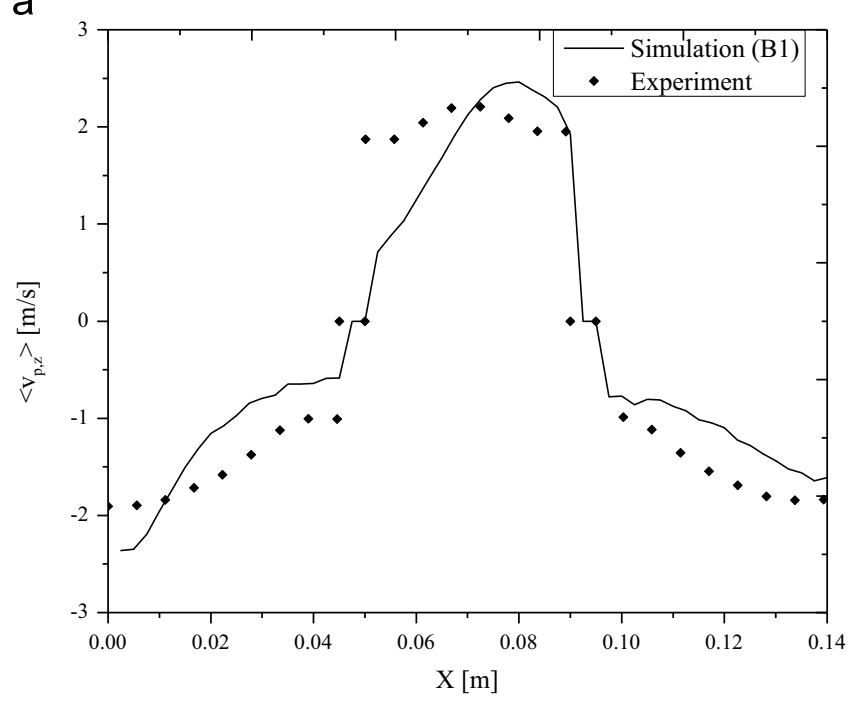

C

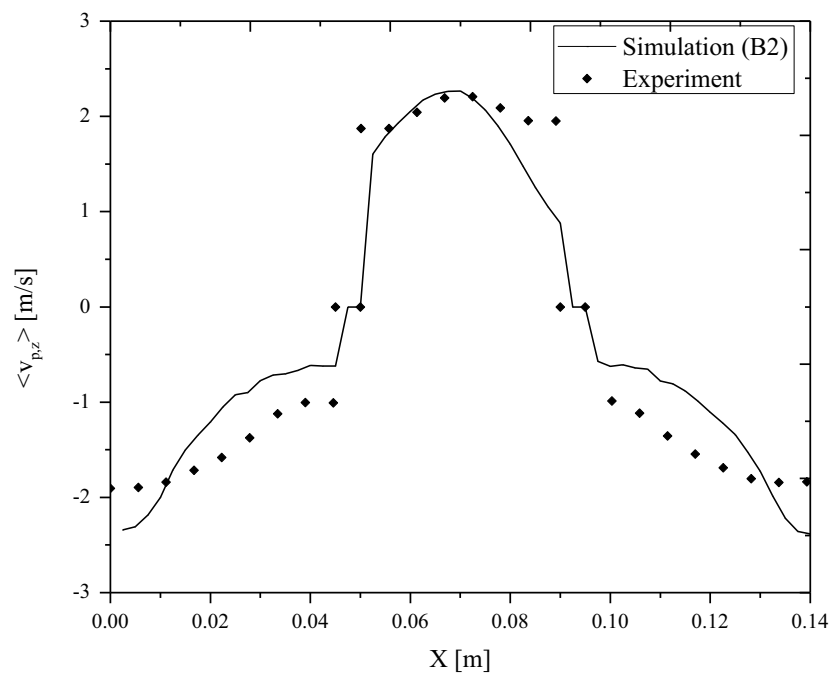

e

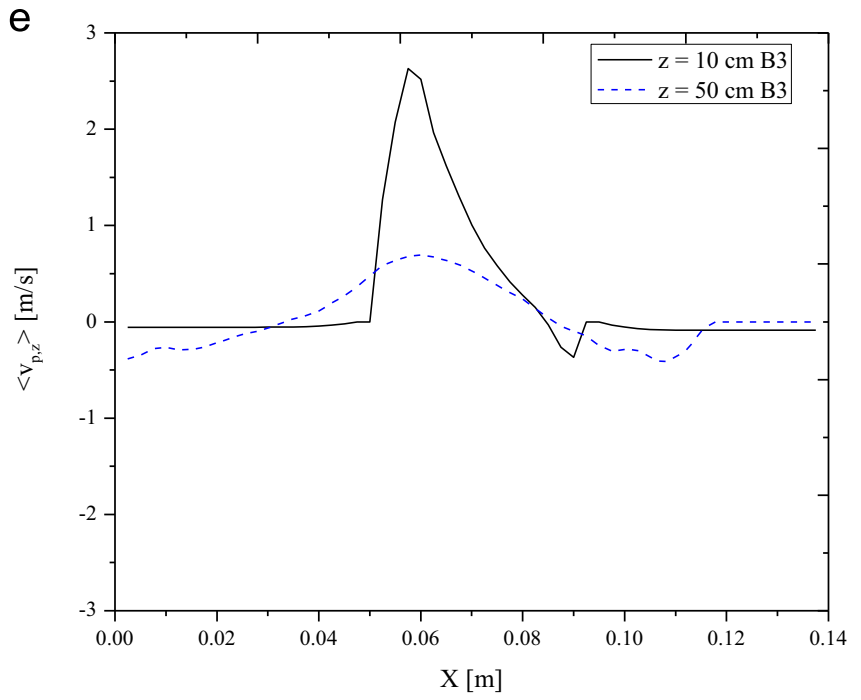

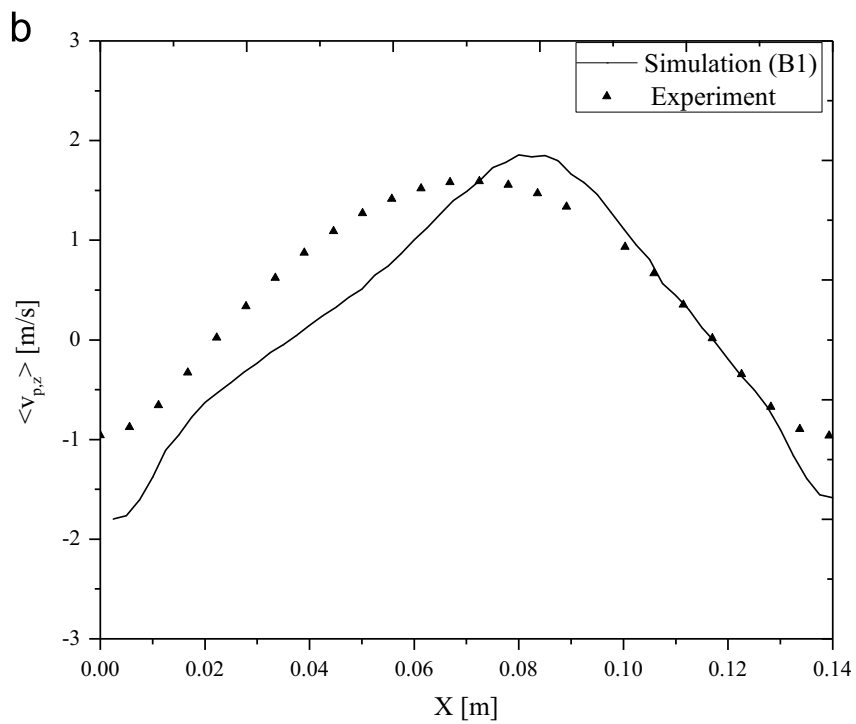

d
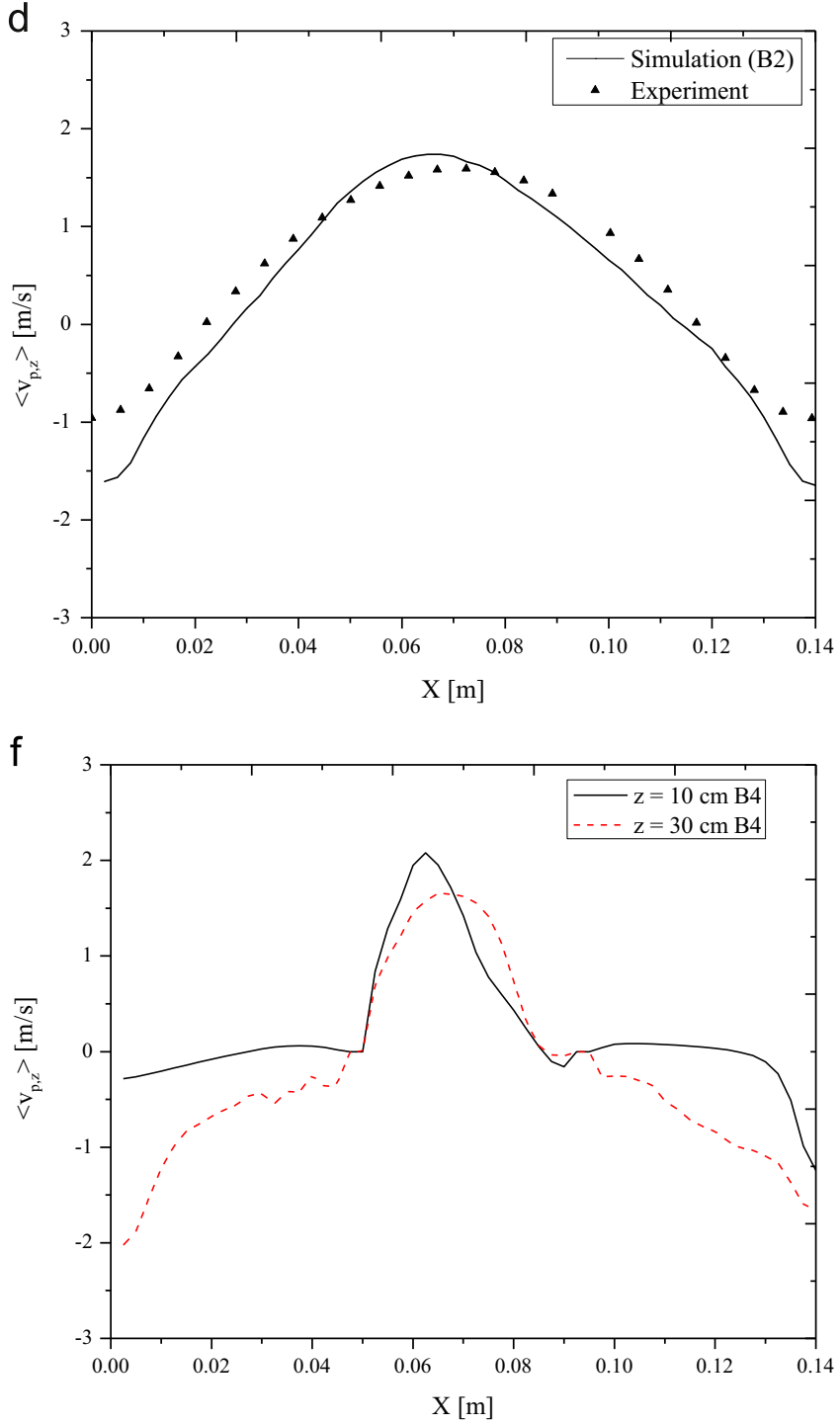

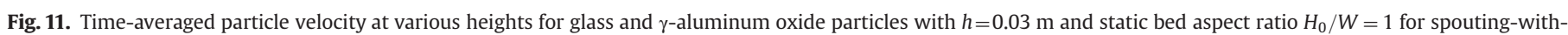

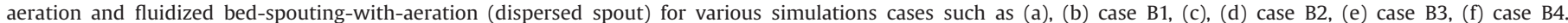
(a) $\mathrm{z}=30 \mathrm{~cm}$, (b) $\mathrm{z}=50 \mathrm{~cm}$, (c) $\mathrm{z}=30 \mathrm{~cm}$, (d) $\mathrm{z}=50 \mathrm{~cm}$, (e) $\mathrm{z}=10,50 \mathrm{~cm}$, (f) $\mathrm{z}=10,30 \mathrm{~cm}$. 
a

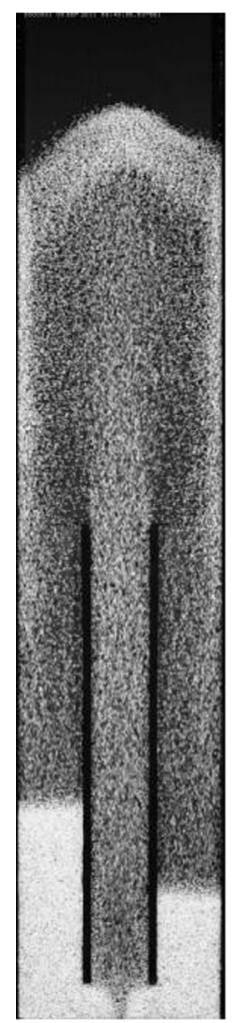

b

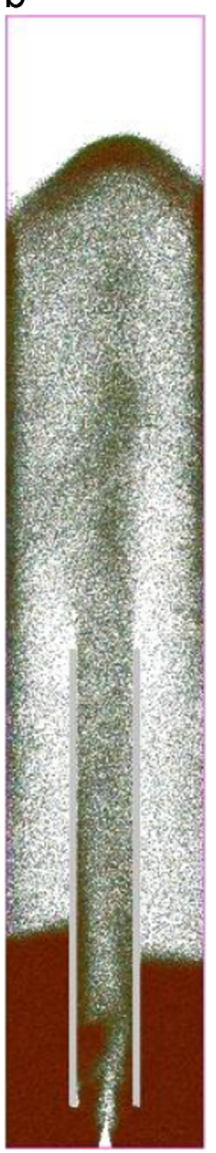

C

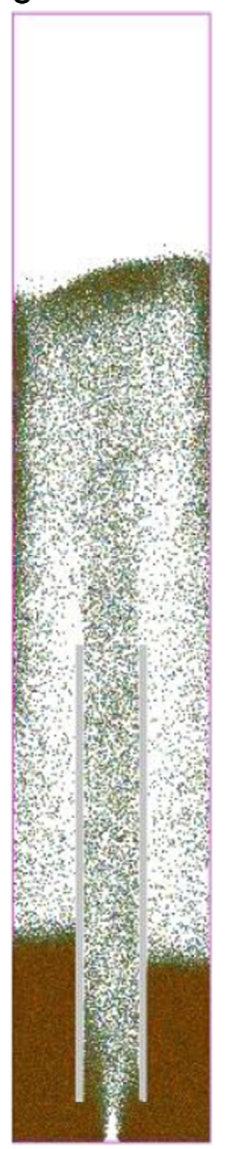

d

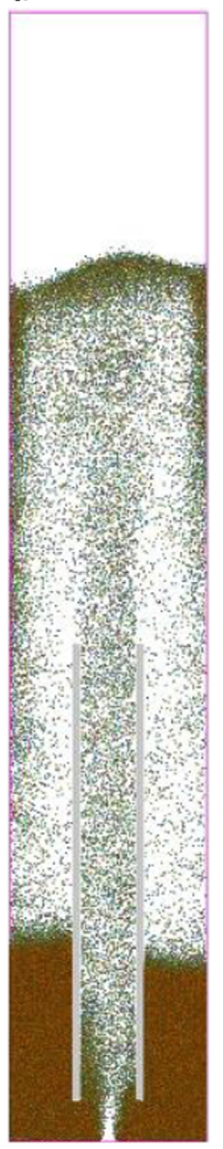

e

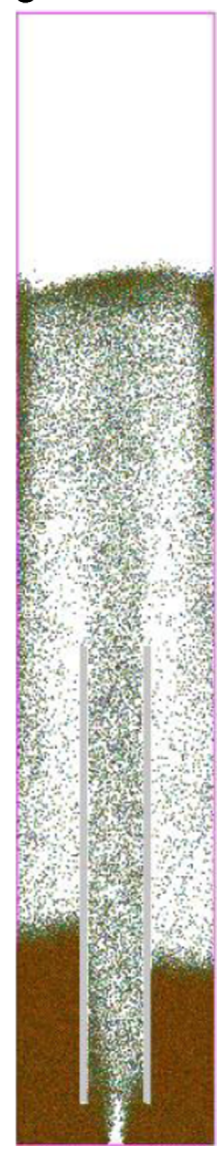

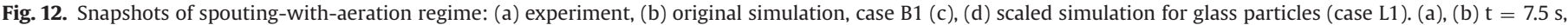
(c) $\mathrm{t}=2 \mathrm{~s}$, (d) $\mathrm{t}=3 \mathrm{~s}$, (e) $\mathrm{t}=6 \mathrm{~s}$.
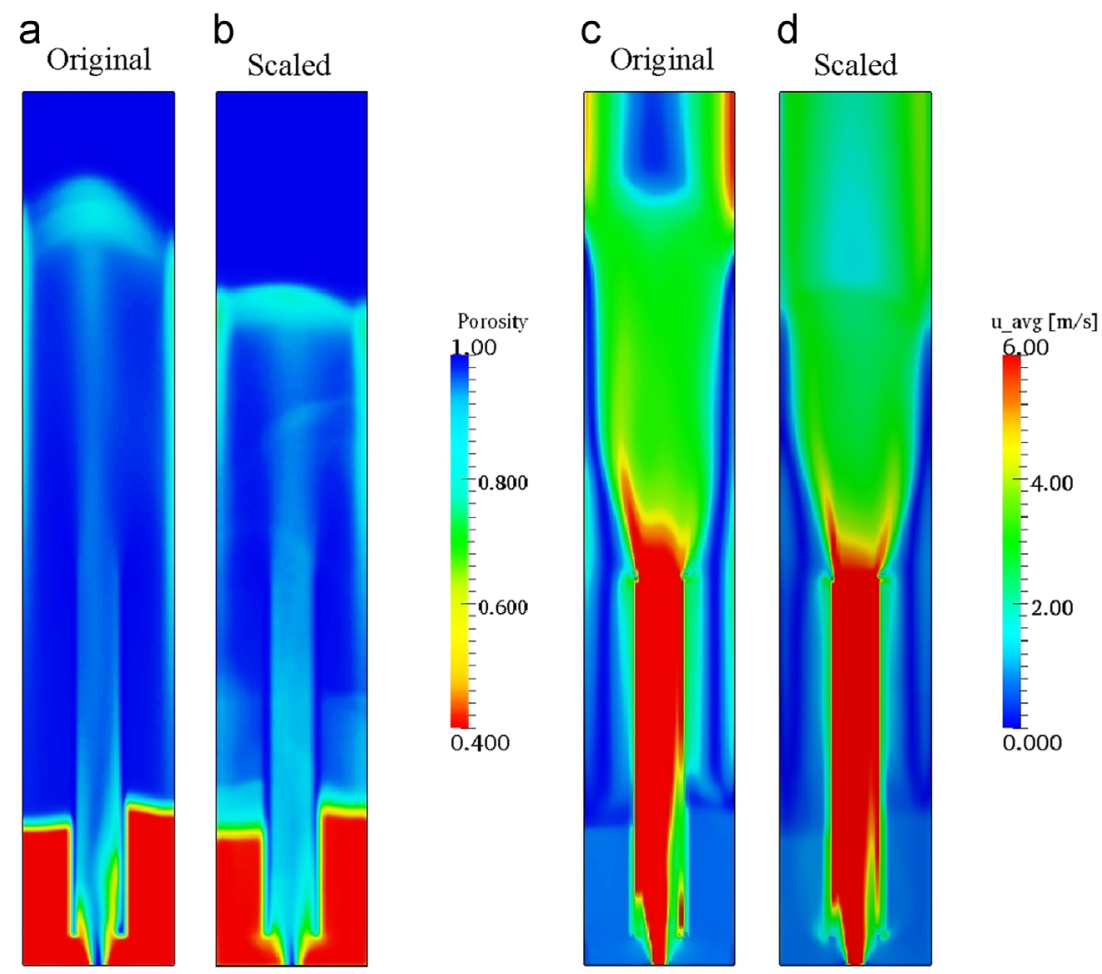

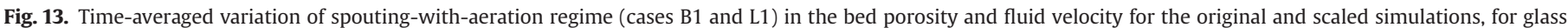
particles. 


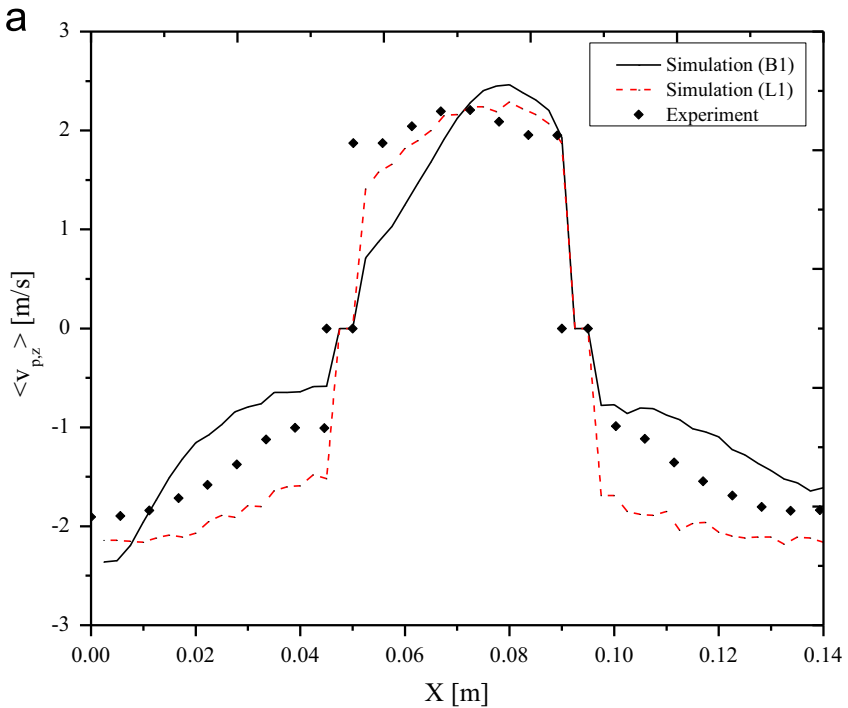

b

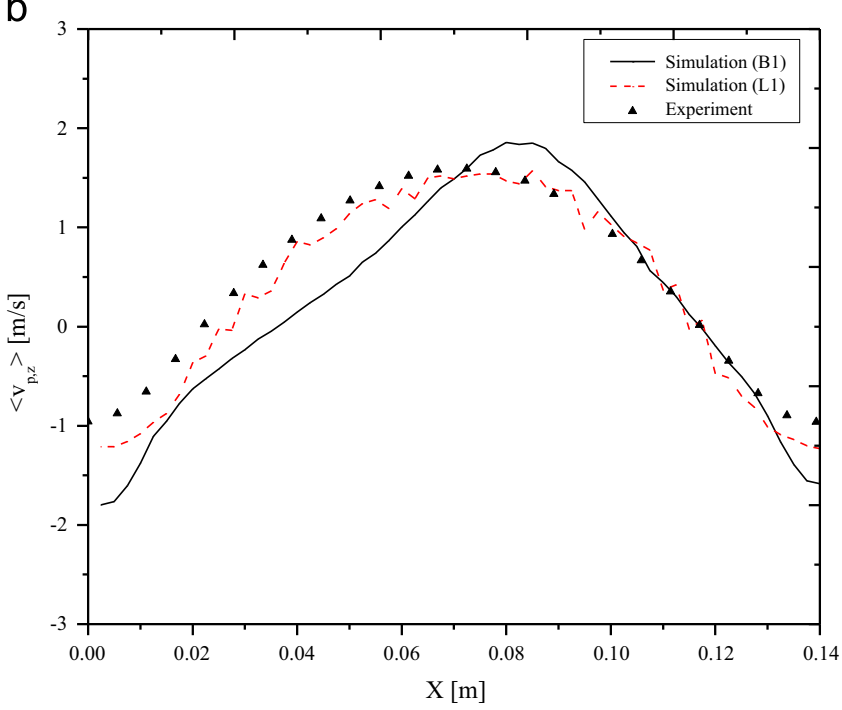

Fig. 14. Comparison of time-averaged particle velocity profiles in the central $x z$-plane for various heights for case B1, L1 and experimental data obtained with PIV. (a) $z=30 \mathrm{~cm}$, (b) $z=50 \mathrm{~cm}$.

formation of dense regions, which partially block the draft plates. This results in unstable spouting with pronounced particle cluster formation with higher gas bypassing through the annulus. Similar flow patterns were observed in the experiments and simulations.

\subsection{Time-averaged particle velocity}

In Fig. 11 the time-averaged particle velocity profiles are presented and compared with the experimental data obtained from PIV measurements.

Fig. 11(a) and (b) shows the comparison for case B1 at various vertical positions and reveal good agreement between simulation and experiments; however in the annulus the agreement slightly detonates. This may be due to the exclusion of rolling friction function. Goniva et al. (2012) reported, increasing the particleparticle and particle-wall rolling friction leads to lower downward the velocity in the annulus without any pronounced effect on the particle velocity in the spout.

In addition, the jet emerging from the draft plates shows a small deflection to the right. For case B2, simulation results at a bed height $z=30$ and $50 \mathrm{~cm}$ show a good agreement with the experimental data (see Fig. 11(c)-(d)). The velocity profiles for

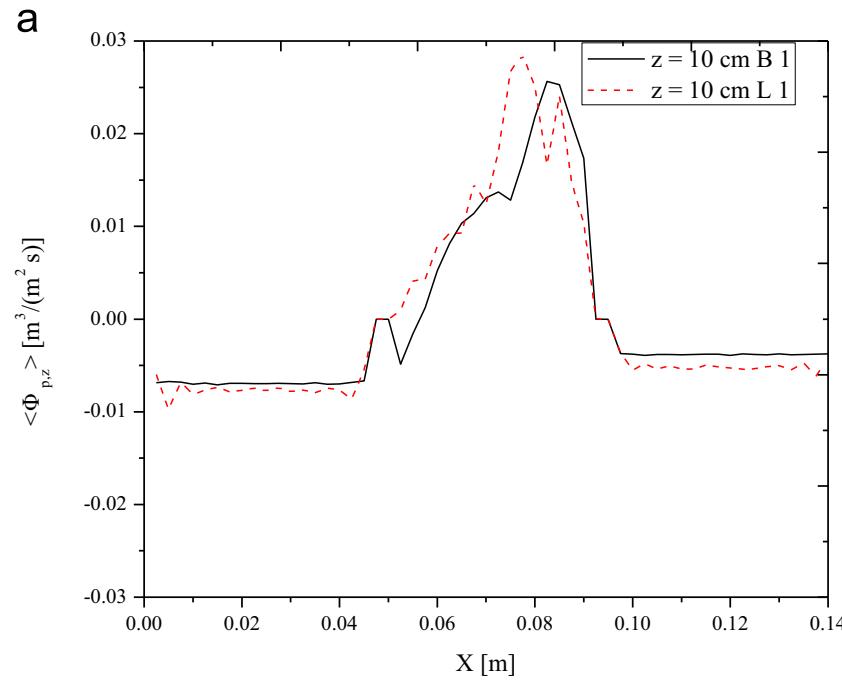

b

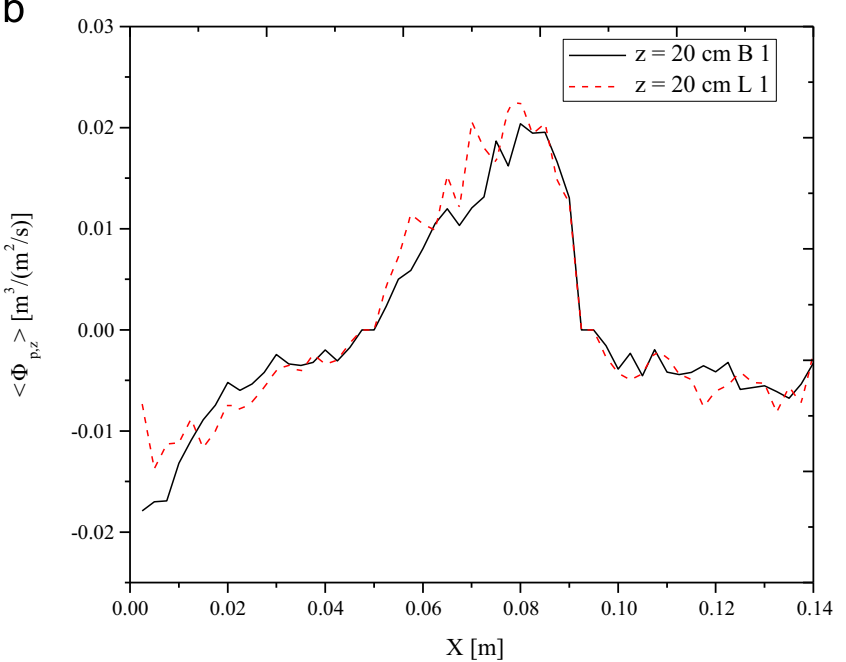

Fig. 15. Time-averaged volumetric particle flux profiles in the central $x z$-plane for various heights (cases B1 and L1). (a) $z=10 \mathrm{~cm}$, (b) $z=20 \mathrm{~cm}$.

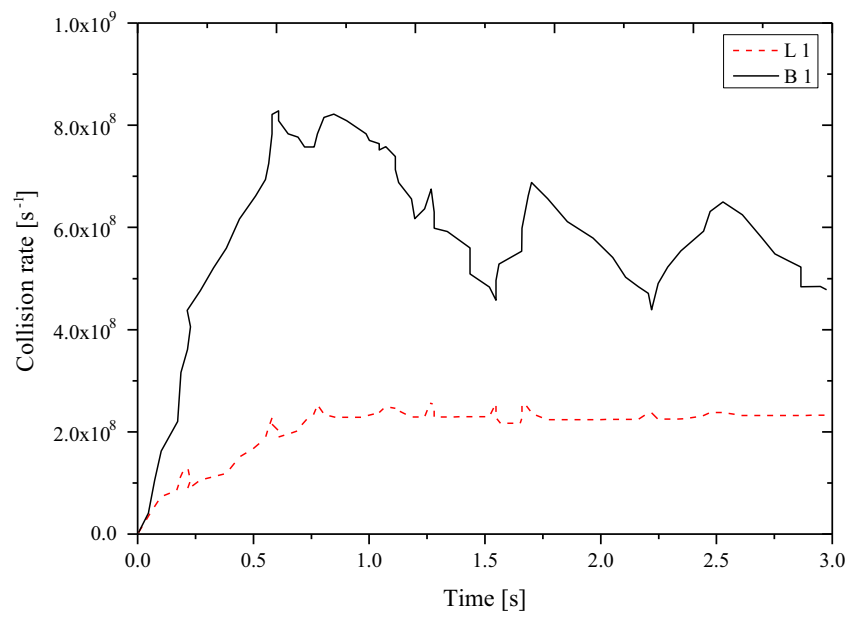

Fig. 16. Variation in collision rate for cases B1 and L1.

cases B3 and B4 are depicted in Fig. 11(e) and (f) at various heights. Note that for cases B3 and B4, only simulation results are shown due lack of available experimental data. The obtained results show slanting of the spout. This is mainly because of formation of 
a

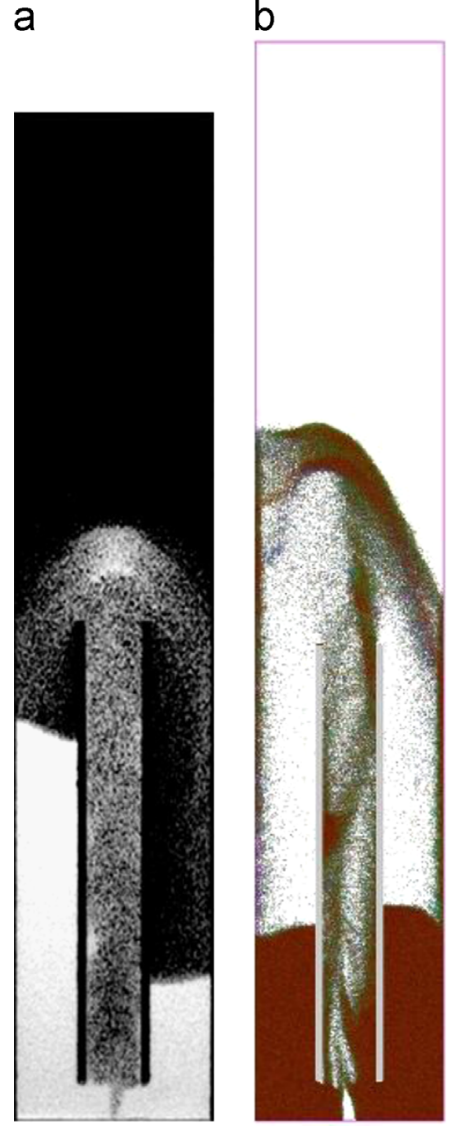

C

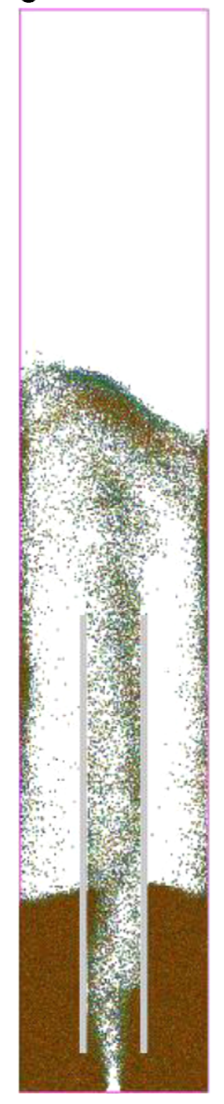

d

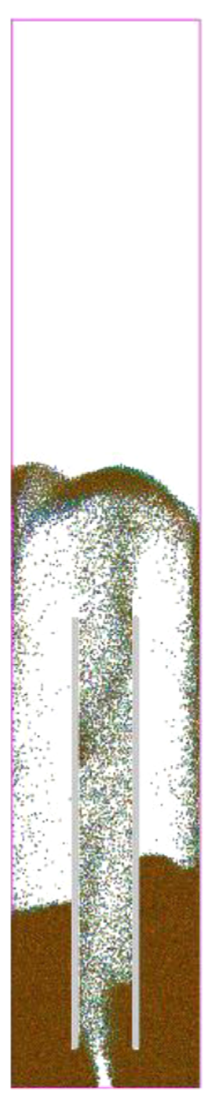

e

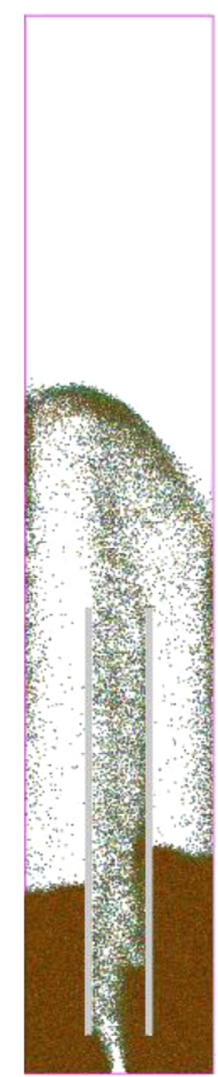

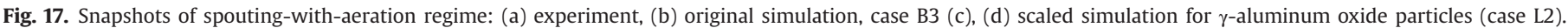
(a) $\mathrm{t}=7.5 \mathrm{~s}$, (b) $\mathrm{t}=7.5 \mathrm{~s}$, (c) $\mathrm{t}=2 \mathrm{~s}$, (d) $\mathrm{t}=3 \mathrm{~s}$, (e) $\mathrm{t}=6 \mathrm{~s}$.
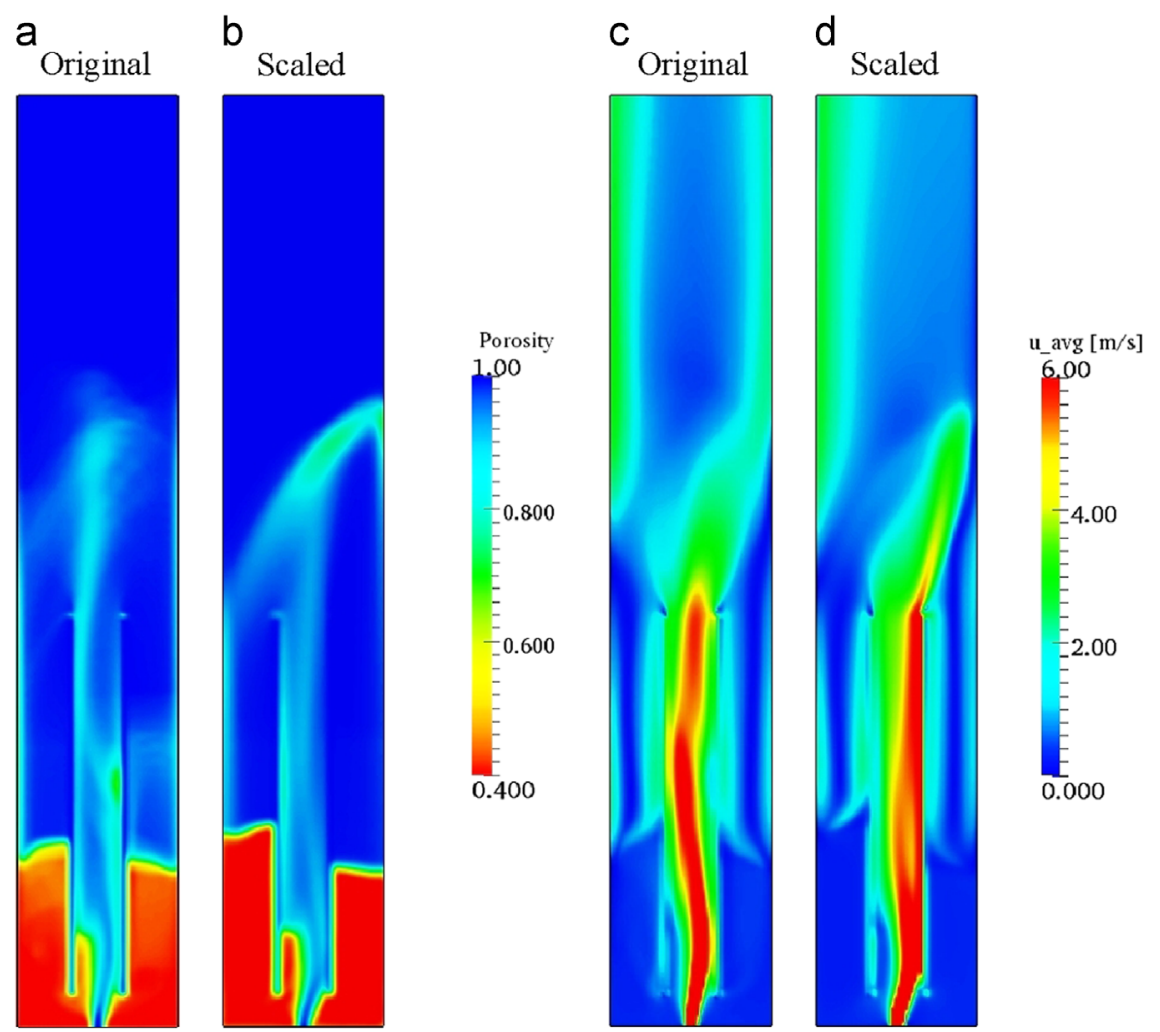

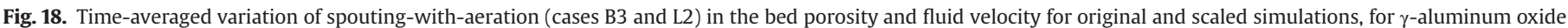
particles. 
particle clusters at various heights in draft plates. Also, clusters formation is more pronounced at lower background velocity.

\subsection{Scaling of simulation}

As discussed earlier, the simulation cases (B1 and B3) involving a greater number of particles were scaled down by applying the scaling approach as discussed in Appendix A. In this section, the computed flow patterns for simulations cases L1 and L2 (with scaled parameters as shown in Table 4) are presented. The results for these cases will be compared with the corresponding simulation cases B1 and B3 (using the actual system properties). For both cases L1 and L2 the simulations were carried out with $5 \times 10^{4}$ particles. For case L1, the simulation results will be compared with the corresponding experimental data obtained from PIV and simulation results obtained with the actual system properties. Whereas for simulations case L2, obtained results were only compared with the simulations performed with original operating parameters.

\subsubsection{Glass particles (B1, L1)}

For the spouting-with-aeration regime, the simulations were performed by changing the physical properties of the glass particles as summarized in Table 4 . The particle diameter was changed from $1 \mathrm{~mm}$ to $2 \mathrm{~mm}$ with subsequent reduction in the density from 2526 to $1263.6 \mathrm{~kg} / \mathrm{m}^{3}$.This results in a decrease of the total number of particles by a factor $2^{3}$ compared to the original system. Fig. 12(a)-(e) shows a comparison between experiments (a), original (b) and scaled (c-e) simulations. As discussed earlier (Section 4.1) for the original simulations, the particles with higher velocities are elevated through the draft plates up to a certain height and fall down in the annulus. Similar particle circulations were observed in the scaled simulations, however with a lower bed height. This may be due to the differences in gas by-passing and particle-particle collision properties, i.e. restitution coefficient. This can be illustrated by considering the time-averaged variation in the bed porosity and the gas velocity along vertical directions, which are shown in Fig. 13. For the original simulations, the spout gas is transported through the draft plates without pronounced gas by-passing from the spout to the annulus. However, in the scaled simulations more pronounced gas by-passing is observed. Consequently, in the scaled simulations, less spout gas is available vertical transport between the draft plates. In Fig. 14 (a) and (b), a more detailed comparison is given for the timeaveraged particle velocity profiles for the simulation using the original system properties (case B1) and the system with the scaled properties (case L1) with experimental data at various bed heights. From this, it can be observed that the time-averaged particle velocity profiles of cases B1 and L1 are in good accordance with the experimental results. The simulation results for both the original and the scaled parameters show stronger resemblance with the experimental finding in spout region as compared with those in the annulus.

In Fig. 15(a)-(c), the time-averaged volumetric particle fluxes for simulations B1 and L1 are shown. From this figure, similar trends can be observed for both cases. Fig. 16 illustrates the variation in collisions rate for cases B1 and L1. The scaled simulation (case L1) shows a reduced collision rate as compared to case B1. This is because the number of particles in case L1 has been reduced by a factor $2^{3}$. The ratio of the collision rates for cases B1 and L1 is approximately equal to 3 .

\subsection{2. $\gamma$-Aluminum oxide particles (B3, L2)}

In this case, the simulations were performed by changing the physical properties of the $\gamma$-aluminum oxide particles as summarized in Table 4. The particle diameter was changed from $1 \mathrm{~mm}$ to $2 \mathrm{~mm}$ with subsequent reduction in the density from 1040 to $520.6 \mathrm{~kg} / \mathrm{m}^{3}$. This results in a decrease of the total number of particles by $2^{3}$ compared to the original system. Snapshots obtained from the simulation are shown in Fig. 17. As mentioned earlier (Section 4.2), similar circulatory flow patterns are observed, in which particles are transported in the upward direction between the draft plates, whereas downward motion can be observed in the annulus. In this case, soon a relatively stable flow pattern is established compared to the simulations performed with the original parameters.

The variation in the bed porosity and the gas velocities for the scaled and original simulations is shown in Fig. 18. Both the scaled and original simulations illustrate the spout meandering with pronounced formation of particle clusters. Furthermore, the scaled simulations show unequal particle distributions in the annulus, which is not observed in the original simulations. This may be due to the reduced gas by-passing from the spout to the annulus. It is noted that, the scaled and original simulations result in a comparable bed height, which is in contrast with the glass particles. This may be due to the extent of gas by-passing and the rate of cluster formations. For $\gamma$-aluminum oxide particles the original simulations with a higher number of the particles show pronounced particle clusters inside the draft plates with a partial spout blocking. This leads to gas by-passing from the spout to annulus,
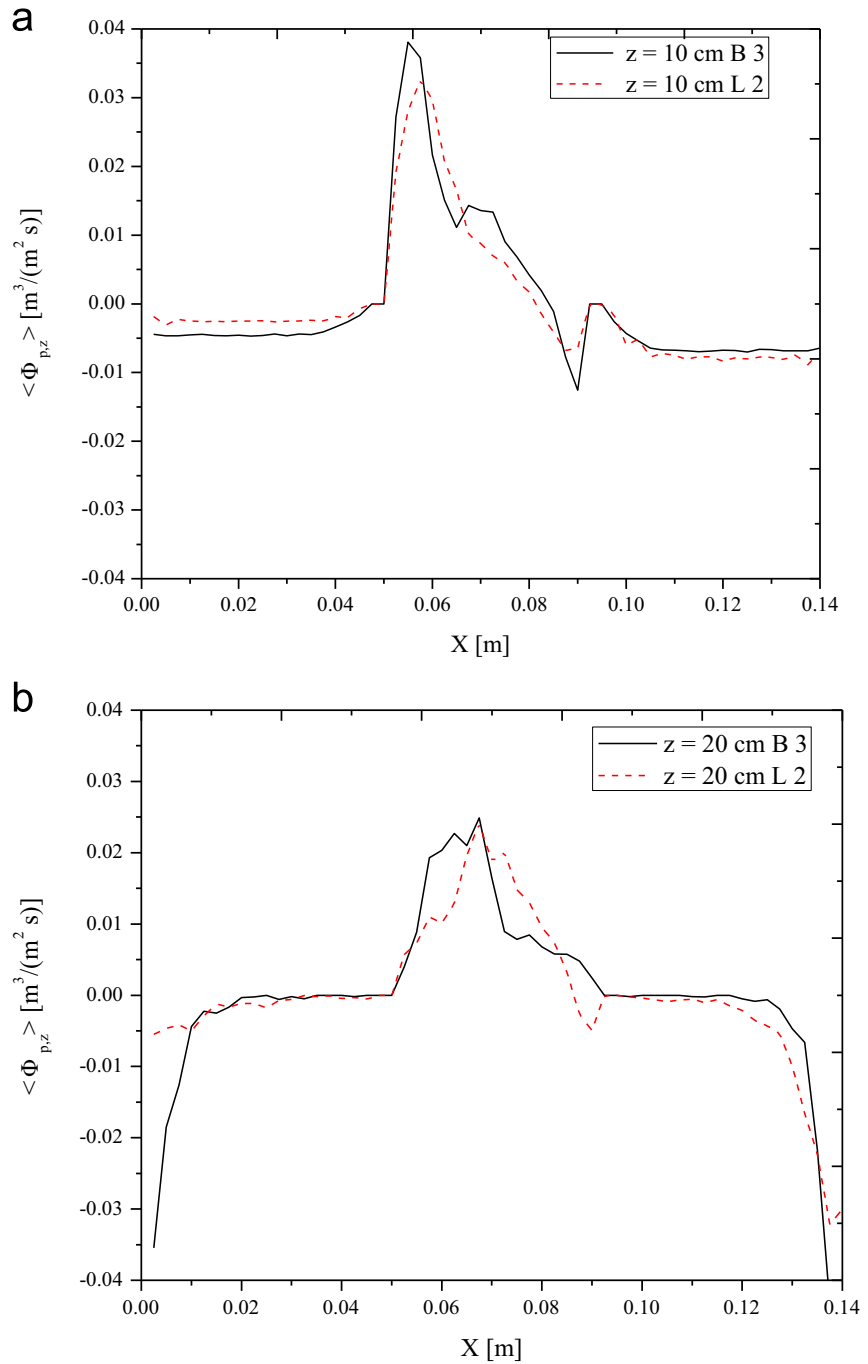

Fig. 19. Profiles of the time-averaged vertical volumetric particle flux in the central $x z$ plane for various heights (case B3 and L2). (a) $z=10 \mathrm{~cm}$, (b) $z=20 \mathrm{~cm}$. 


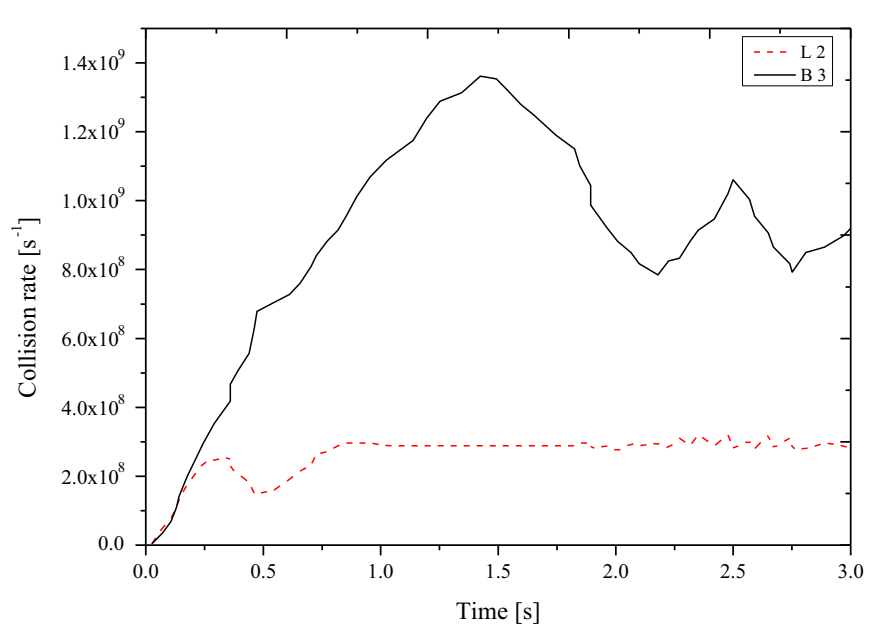

Fig. 20. Variation in collision rate for cases B3 and L2.

eventually leading to a lower bed height. Although the scaled simulations with a lower number of particles show particle cluster inside the draft plates, it does not lead to a partial spout blocking, but to lower gas by-passing and a higher bed height. This is in contrast with the scaled simulations of the glass particles.

Fig. 19 shows the evolution in the time-averaged volumetric particle flux for cases B3 and L2 as a function of the vertical position. Similar trends are observed in the draft tube at $z=10$ and $20 \mathrm{~cm}$. However, in the annulus (especially near the wall) slight variation is observed which may be due to the higher solid volume fraction of the scaled case arises due to wall effects.

The variation in the collision rate for cases B3 and L2 is shown in Fig. 20. Case L2 shows a reduced collision rate as compared with case B3. This is because the numbers of particles in the case L2 were lower by a factor $2^{3}$. For $\gamma$-aluminum oxide relatively higher numbers of collisions were obtained compared to the glass particles. This is due to differences in restitution coefficient and density. As explained earlier, the particles with lower restitution coefficient have greater tendencies to form the dense regions (that is with lower particle-particles distances).

\section{Conclusions}

Simulations for a spout fluidized bed with draft plates were carried out using a discrete particle model (DPM). In our model the gas phase dynamics were described by the volume-averaged Navier-Stokes equations; whereas the individual particle motions were determined by Newton's laws of motion. The particleparticle and particle-wall encounters are represented using a soft-sphere collision model. The draft plates in the spout fluidized bed were treated as internal walls.

Simulations were performed for two particulate systems, namely glass and $\gamma$-aluminum oxide by selecting two regimes, viz. spoutingwith-aeration and fluidized bed-spouting-with-aeration (dispersed spout). Flow patterns, time-averaged particle velocities and volumetric particle fluxes for glass and $\gamma$-aluminum oxide particles in both the regimes were compared with experimental results. These comparisons show good agreement. Better agreement in the annulus may be achieved by including a rolling friction model.

Furthermore, a scaling approach was applied to reduce the total computational time involving higher number of particles while maintaining similar bed characteristics. The obtained results were compared with the experimental and original DPM simulations (corresponding to the original system) and showed a overall good agreement in the flow patterns and volumetric particle fluxes with

significantly reduced computational time. The reduction in the total computational time was mainly attributed to the reduced number of collisions, by a factor 3. So the scaling approach is a good alternative to study the systems dynamics involving large number of particles. For both materials, the variation in the bed height is highly influenced by the extent of gas by-passing and the rate of cluster formation. For the glass particles, the scaled simulations show a reduced bed height compared to the unscaled case. This may be due to the pronounced gas-bypassing from the spout to the annulus. However, the scaled simulations for the $\gamma$ aluminum oxide particle show a comparable bed height with the original simulations, which may be due to the lower restitution coefficient, resulting in the formation of dense regions with partial spout blocking.

\section{Nomenclature}

$a$

$\mathrm{Ar}$

$c$

$C_{d}$

$C_{S}$

$D$

$d_{\text {cube }}$

$d_{p}$

$e_{n}$

$e_{t}$
$f_{j}^{\text {cube }}$

$g$

$f_{\text {cell }}^{i}$

H

M

$M_{\text {avg }}$

$m_{p}$

$N_{p}$

$k$

$k_{n}$

$p_{g}$

$R$

$R_{a}$

$\mathrm{Re}$

$\operatorname{Re}_{p}$

$R_{F}$

$S_{p}$

$\mathbf{s}_{\mathbf{p}}$

$T$

$\Delta t$

$\Delta t_{p}$

$\mathbf{T}_{p}$

$\Delta t_{g}$

$u_{b g}$

$u_{g}$

$u_{m f}$

$u_{s p}$

$V_{\text {cell }}$

$V_{p}$

$\mathbf{v}_{\mathbf{p}}$

$W$

$\Delta x$

$\Delta y$

$\Delta z$

$\varepsilon_{\mathrm{g}}$ ratio of cube diameter to particle diameter, dimensionless

Archimedes number, dimensionless

V-SGS model constant, dimensionless

drag coefficient, dimensionless

Smagorinsky constant, dimensionless

depth of the bed, $m$

size of the cube, $m$

diameter of the particle, $m$

coefficient of normal restitution, dimensionless

coefficient of tangential restitution, dimensionless

volume fraction of $j$ cell occupied by the cube, dimensionless acceleration due to gravity, $\mathrm{m} / \mathrm{s}^{2}$

volume fraction of the cell $i$ occupied by the cube, dimensionless

height of the bed, $\mathrm{m}$

image magnification factor, dimensionless

average molecular weight

particle mass, $\mathrm{kg}$

number of particles, dimensionless

scaling factor, dimensionless

normal spring stiffness, $\mathrm{N} / \mathrm{m}$

gas pressure, $\mathrm{Pa}$

universal gas constant, $\mathrm{J} /(\mathrm{mol} \mathrm{K})$

radius of the particle $a, m$

Reynolds number, dimensionless

particle Reynolds number, dimensionless

correlation between the mean and fluctuating image intensities, dimensionless

source term, dimensionless

average particle displacement, $\mathrm{m}$

temperature of gas, $\mathrm{K}$

time interval, $s$

time step for particle, $s$

torque on the particle, $\mathrm{Nm}$

time step for gas, $\mathrm{s}$

background gas velocity, $\mathrm{m} / \mathrm{s}$

gas velocity, $\mathrm{m} / \mathrm{s}$

minimum fluidization velocity, $\mathrm{m} / \mathrm{s}$

spout gas velocity, $\mathrm{m} / \mathrm{s}$

volume of cell, $\mathrm{m}^{3}$

particle volume, $\mathrm{m}^{3}$

particle velocity, $\mathrm{m} / \mathrm{s}$

width of the bed, $m$

grid size in the $x$ direction, $\mathrm{m}$

grid size in the $y$ direction, $\mathrm{m}$

grid size in the $z$ direction, $m$

gas volume fraction, dimensionless 
$\rho_{g} \quad$ density of the gas, $\mathrm{kg} / \mathrm{m}^{3}$

$\rho_{s} \quad$ density of the solid, $\mathrm{kg} / \mathrm{m}^{3}$

$\varepsilon_{s} \quad$ solid volume fraction, dimensionless

$\beta \quad$ momentum transfer coefficient, $\mathrm{kg} / \mathrm{m}^{3} \mathrm{~s}$

$\delta \quad$ distribution function, dimensionless

$\omega_{p} \quad$ angular velocity, $\mathrm{s}^{-1}$

$\varepsilon_{p}^{2 D} \quad$ 2D particle distribution, dimensionless

$\varepsilon_{\text {cube }} \quad$ porosity of the cube, dimensionless

$\phi_{E} \quad$ variable on Eulerian grid, dimensionless

$\phi_{L} \quad$ variable on Lagrangian grid, dimensionless

$\mu_{g} \quad$ dynamic viscosity of the gas, $\mathrm{kg} / \mathrm{m} \mathrm{s}$

$\mu_{\text {tur }} \quad$ shear induced turbulent viscosity, $\mathrm{kg} / \mathrm{m} \mathrm{s}$

$\Delta \quad$ filter width, dimensionless

|S| characteristic filtered strain, dimensionless

$\alpha \quad(3 \times 3)$ matrix of the derivatives of the filtered velocity $\mathbf{u}_{g}$, dimensionless

$\nu_{\mathrm{g}} \quad$ kinematic viscosity of gas, $\mathrm{m}^{2} / \mathrm{s}$

$\left\langle\mathrm{v}_{p, z}\right\rangle \quad$ time-averaged particle velocity, $\mathrm{m} / \mathrm{s}$

$\left\langle\Phi_{p, z}\right\rangle \quad$ time-averaged particle flux, $\mathrm{m}^{3} /\left(\mathrm{m}^{2} \mathrm{~s}\right)$

\section{Acknowledgments}

This research is supported by the Dutch Technology Foundation STW, applied science division of NWO and the Technology Program of the Ministry of Economic Affairs in The Netherlands, as well as by the DFG (German Research Foundation) in Germany.

\section{Appendix A}

\section{Ar and Re are given by}

$\operatorname{Ar}=\frac{\text { Gravitational forces }}{\text { Viscous forces }}=\frac{g d_{p}^{3}}{\nu_{g}^{2}} \frac{\left(\rho_{p}-\rho_{g}\right)}{\rho_{g}}$

$\operatorname{Re}=\frac{\text { Inertial forces }}{\text { Viscous forces }}=\frac{d_{p}\left(\mathbf{u}_{g}-\mathbf{v}_{p}\right)}{\nu_{g}}$

where $\nu_{g}\left(=\mu_{g} / \rho_{g}\right)$ is the kinematic viscosity of the gas. The actual and the computational particle diameter are indicated with subscripts 1 and 2 respectively.

$k=\frac{d_{p, 2}}{d_{p, 1}}=\frac{\text { Computational particle diameter }}{\text { Actual particle diameter }}$

In order to maintain the same minimum fluidization velocity, the particle Reynolds number was assumed to be constant as

$u_{m f, 1}=u_{m f, 2}=\frac{\operatorname{Re}_{m f, 1} \nu_{g, 1}}{d_{p, 1}}=\frac{\operatorname{Re}_{m f, 2} \nu_{g, 2}}{d_{p, 2}}$

So, the scaled dynamic viscosity for the simulation can be defined as follows:

$\nu_{g, 2}=\frac{d_{p, 2}}{d_{p, 1}} \nu_{g, 1}=k \nu_{g, 1}$

Now using this kinematic viscosity, the particle density can be modified to a maintain constant Archimedes number by assuming a constant gas density.

$\frac{g d_{p, 1}^{3}}{\nu_{g, 1}^{2}} \frac{\left(\rho_{p, 1}-\rho_{g, 1}\right)}{\rho_{g, 1}}=\frac{g d_{p, 2}^{3}}{\nu_{g, 2}^{2}} \frac{\left(\rho_{p, 2}-\rho_{g, 2}\right)}{\rho_{g, 2}}$

On introducing the particle size ratio $k$ and simplifying the above equation, the new scaled particle density to be used for the simulations can be obtained as follows:

$\rho_{p, 2}=\frac{\rho_{g, 2}}{k} \frac{\left(\rho_{p, 1}-\rho_{g, 1}\right)}{\rho_{g, 1}}+\rho_{g, 2}$

\section{References}

Antonyuk, S., Heinrich, S., Deen, N.G., Kuipers, J.A.M., 2009. Influence of liquid layers on energy absorption during particle impact. Particuology 7, 245-259.

Beetstra, R., van der Hoef, M.A., Kuipers, J.A.M., 2007. Drag force of intermediate Reynolds number flow past mono- and bidisperse arrays of spheres. AIChE J. 53 489-501.

Chatterjee, A., 1970. Spout-fluid bed technique. Ind. Eng. Chem. Process Des. Dev. 9, 340-341.

Claflin, J.K., Fane, A.G., 1983. Spouting with a porous draft-tube. Can. J. Chem. Eng. $61,356-363$.

Deen, N.G., van Sint Annaland, M., Kuipers, J.A.M., 2004. Multi-scale modelling of dispersed gas-liquid two-phase flow. Chem. Eng. Sci. 59, 1853-1861.

Deng, Z., Xiao, R., Jin, B., Huang, H., Shen, L., Song, Q., Li, Q., 2008. Computational fluid dynamics modeling of coal gasification in a pressurized spout-fluid bed. Energy Fuels 22, 1560-1569.

Epstein, N., Grace, J.R., 2011. Spouted and spout Fluid Beds. Cambridge University Press, pp. 29-54.

Ergun, S., 1952. Fluid flow through packed columns. Chem. Eng. Prog. 48, 89-94.

Goniva, C., Kloss, C., Deen, N.G., Kuipers, J.A.M., Pirker, S., 2012. Influence of rolling friction on single spout fluidized bed simulation. Particuology 10, 582-591.

Hoomans, B.P.B., Kuipers, J.A.M., Briels, W.J., van Swaaij, W.P.M., 1996. Discrete particle simulation of bubble and slug formation in a two-dimensional gasfluidised bed: a hard-sphere approach. Chem. Eng. Sci. 51, 99-118.

Ishikura, T., Nagashima, H., Ide, M., 2003. Hydrodynamics of a spouted bed with a porous draft tube containing a small amount of finer particles. Powder Technol. 131, 56-65.

Kazari, M., Roko, K., Kawaguchi, T., Tanaka, T., Tsuji, Y., 1995. A study on conditions for similarity of particle motion in numerical simulation of dense gas-solid two phase flow. In: Proceedings of the 2nd International Conference on Multiphase Flow. Kyoto, Japan, pp. 9-15.

Link, J.M., 2006. Development and validation of a discrete particle model of a spoutfluid bed granulator (Ph.D. thesis). University of Twente, The Netherlands.

Link, J.M., Deen, N.G., Kuipers, J.A.M., Fan, X., Ingram, A., Parker, D.J., Wood, J. Seville, J.P.K., 2008. PEPT and discrete particle simulation study of spout-fluid bed regimes. AIChE J. 54, 1189-1202.

Link, J., Zeilstra, C., Deen, N., Kuipers, H., 2004. Validation of a discrete particle model in a 2D spout-fluid bed using non-intrusive optical measuring techniques. Can. J. Chem. Eng. 82, 30-36.

Link, J.M., Godlieb, W., Deen, N.G., Kuipers, J.A.M., 2007. Discrete element study of granulation in a spout-fluidized bed. Chem. Eng. Sci. 62, 195-207.

Link, J.M., Godlieb, W., Tripp, P., Deen, N.G., Heinrich, S., Kuipers, J.A.M., Schönherr, M. Peglow, M., 2009. Comparison of fibre optical measurements and discrete element simulations for the study of granulation in a spout fluidized bed. Powder Technol. 189, 202-217.

Link, J.M., Cuypers, L.A., Deen, N.G., Kuipers, J.A.M., 2005. Flow regimes in a spoutfluid bed: a combined experimental and simulation study. Chem. Eng. Sci. 60 3425-3442.

Mokhtar, M., Kuwagi, K., Takami, T., Hirano, H., Horio, M., 2012. Validation of the similar particle assembly (SPA) model for the fluidization of Geldart's group A and D particles. AIChE J. 58, 87-98.

Mudde, R.F., 2011. Bubbles in a fluidized bed: a fast X-ray scanner. AIChE J. 57, 2684-2690.

Ren, B., Zhong, W., Jin, B., Yuan, Z., Lu, Y., 2011. Modelling of gas-particle turbulent flow in spout-fluid bed by computational fluid dynamics with discrete element method. Chem. Eng. Technol. 34, 2059-2068.

Sakai, M., Yamada, Y., Shigeto, Y., Shibata, K., Kawasaki, V.M., Koshizuka, S., 2010. Large-scale discrete element modeling in a fluidized bed. Int. J. Numer. Methods Fluids 64, 1319-1335.

Sakano, H.M., Yaso, T., 2000. Numerical simulation of two-dimensional fluidized bed using discrete element method with imaginary sphere model. Jpn. J. Multiphase Flow 14, 66-73.

Smagorinsky, J., 1963. General circulation experiments with the primitive equations. Mon. Weather Rev. 91, 99-164.

Snider, D.M., 2001. An incompressible three-dimensional multiphase particle-incell model for dense particle flows. J. Comput. Phys. 170, 523-549.

Sutkar, V.S., Deen, N.G., Kuipers, J.A.M., 2013a. Spout fluidized beds: recent advances in experimental and numerical studies. Chem. Eng. Sci. 86, 124-136.

Sutkar, V.S., van Hunsel, T.J.K., Deen, N.G., Salikov, V., Antonyuk, S., Heinrich, S. Kuipers, J.A.M., 2013b. Experimental investigations of a pseudo-2D spout fluidized bed with draft plates. Chem. Eng. Sci. 102, 524-543.

Tsuji, T., Yabumoto, K., Tanaka, T., 2008. Spontaneous structures in threedimensional bubbling gas-fluidized bed by parallel DEM-CFD coupling simulation. Powder Technol. 184, 132-140.

van Buijtenen, M.S., Börner, M., Deen, N.G., Heinrich, S., Antonyuk, S., Kuipers, J.A.M. 2011b. An experimental study of the effect of collision properties on spout fluidized bed dynamics. Powder Technol. 206, 139-148. 
van Buijtenen, M.S., Deen, N.G., Heinrich, S., Antonyuk, S., Kuipers, J.A.M., 2009a. Discrete particle simulation study on the influence of the restitution coefficient on spout fluidized-bed dynamics. Chem. Eng. Technol. 32, 454-462.

van Buijtenen, M.S., Deen, N.G., Heinrich, S., Antonyuk, S., Kuipers, J.A.M., 2009b. A discrete element study of wet particle-particle interaction during granulation in a spout fluidized bed. Can. J. Chem. Eng. 87, 308-317.

van Buijtenen, M.S., Buist, K., Deen, N.G., Kuipers, J.A.M., Leadbeater, T., Parker, D.J. 2012. Numerical and experimental study on spout elevation in spout-fluidized beds. AIChE J. 58, 2524-2535.

van Buijtenen, M.S., van Dijk, M.S., Deen, N.G., Kuipers, J.A.M., Leadbeater, T., Parker, D.J., 2011a. Numerical and experimental study on multiple-spout fluidized beds. Chem. Eng. Sci.66, 2368-2376. van der Hoef, M.A., van Sint Annaland, M., Andrews, A.T., Sundaresan, S., Kuipers, J.A.M., 2008. Multiscale modelling of gas-fluidized beds. Adv. Chem. Eng. 31, 65-149.

Vreman, A., 2004. An eddy-viscosity subgrid-scale model for turbulent shear flow: algebraic theory and applications. Phys. Fluids 16, 3670-3681.

Zhang, Y., Jin, B., Zhong, W., Ren, B., Xiao, R., 2010. DEM simulation of particle mixing in flat-bottom spout-fluid bed. Chem. Eng. Res. Des. 88, 757-771.

Zhong, W., Xiong, Y., Yuan, Z., Zhang, M., 2006. DEM simulation of gas-solid flow behaviors in spout-fluid bed. Chem. Eng. Sci. 61, 1571-1584

Zhong, W., Zhang, M., Jin, B., Yuan, Z., 2007. Flow behaviors of a large spout-fluid bed at high pressure and temperature by 3D simulation with kinetic theory of granular flow. Powder Technol. 175, 90-103. 